\title{
Cambridge Geotechnical Centrifuge Operations
}

\author{
A. N. SCHOFIELD*
}

The Cambridge Geotechnical Centrifuge routinely tests models made of up to $0.2 \mathrm{~m}^{3}$ of soil, at accelerations up to $125 \mathrm{~g}$. Self-weight effects in models and in corresponding prototypes are similar within a few per cent. Seepage and diffusion of pore water into the plane section of an unlined tunnel serve to illustrate scaling relationships. The stress/strain behaviour of soil alters with change of effective pressure $p^{\prime}$ and specific volume $v$. A theory of plasticity explains consolidation and yielding in shear at states above critical, but failures below critical state involve rupture or fracture. The range of values of a new equivalent liquidity $L I_{5}=L I+0.5 \log \left(p^{\prime} / 5\right)$ associated with yielding is $1.9<L I_{5}<1$, with rupture is $1<L I_{5}<0.5$, and with fracture is $0.5<L I_{5}$. One example of centrifuge modelling is for tunnels in soft ground near critical states $\left(L I_{5}=1\right)$, in which plastic collapse is observed closely to match upper and lower bound calculations of theory of plasticity. In contrast, another example of centrifuge modelling is of flowsliding in ground further from critical states. In two fanrous cases-Mississippi River Bank flowslides and Champlain Sea quick clay flowslides-model tests suggest that at the moment of failure it is the sudden occurrence of fissures that destabilizes ground when its permeability greatly increases.
La Centrifugeuse Géotechnique de Cambridge effective à des essais routine de modèles de sol, pouvant atteindre un volume de $0.2 \mathrm{~m}^{3}$ et des accélérations $125 \mathrm{~g}$. Les effets du poids intrinsèque, dans le cas des modèles et des prototypes correspondants, ont été identiques à quelques pour cent près. L'infiltration et la diffusion de l'eau interstitielle dans la section plane d'un tunnel non enduit servent à illustrer les relations d'échelle. Le comportement contrainte/déformation du sol varie en fonction du changement de la pression effective $p^{\prime}$ et du volume spécifique $V$. Une théorie de plasticité explique la consolidation et le fluage cisaillement à des états au-dessus du niveau critique mais, en dessous de ce niveau, il y a rupture ou fracture. Comme gamme de valeurs d'une nouvelle liquidité équivalente $L I^{5}=$ $L I+0.5 \log \left(p^{\prime} / 5\right)$ associée au fluage, nous avons $1.9<L I^{5}<1$; dans le cas de la rupture, nous avons $1<L I^{5}<0.5$ et dans le cas de fracture, $0.5 L^{5}$. Un des exemples de modélisation en centrifugeuse concerne des tunnels en sol mou s'approchant des états critiques $\left(L I^{5}=1\right)$, pour lesquels on peut observer que l'affraissement plastique correspond très sensiblement aux etats limites inferieurs et supérieurs de la théorie de plasticité. Par contraste, un autre exemple de modélisation en centrifugeuse que l'on donne concerne les glissements par liquéfaction dans des terrains dont l'état n'est pas aussi proche de l'état critique. Dans deux cas bien connus, à savior les glissements par liquéfaction des Berges de la Rivière Mississippi et ceux de l'argile sensible de la Mer Champlain, les essais de modèles conduisent à penser qu'au moment de la rupture, c'est l'apparition brusque de fissures qui provoque la déstabilisation du terrain au moment où sa perméabilité s'accroît considérablement.

\section{INTRODUCTION}

This lecture will be in two parts: the first half aims to give a basis for discussion of centrifuge operations-describing details of centrifuge construction, mechanics of models and remoulded soil behaviour. The second half will discuss a selection of tests, first on tunnels in soft ground and then on flowslides and fractures.

\section{DETAILS OF CENTRIFUGE CONSTRUCTION}

Since the topic of this lecture is the recent operation of one particular centrifuge the discussion of earlier and other facilities or operations should be left to another occasion. A

\footnotetext{
* Department of Engineering, Cambridge University.
} 
convenient point at which to begin this account is 1969 when the proposal to build a machine with a $10 \mathrm{~m}$ rotor arm was made by the late Professor K. H. Roscoe, who was granted $£ 40000$ towards its construction by SRC.

The machine was designed in detail by Mr P. W. Turner, Design Engineer of Cambridge University Engineering Department, and construction was executed under the direction of Dr R. G. James in a pit on the West Cambridge site, about 2 miles from our main laboratory (see Appendix 2). For safety, a reinforced concrete structure was designed to house the machine (Fig. 1). The circular chamber (Fig. 2) is a little over $10 \mathrm{~m}$ diameter and $2 \mathrm{~m}$ high. The $10 \mathrm{~m}$ rotor arm rotates in this chamber at speeds up to $180 \mathrm{rpm}$. The motor drive set is placed below the bottom bearing of the rotor. Ground level is about $2 \mathrm{~m}$ above the top bearing of the rotor; the centrifuge chamber is therefore buried below $2 \mathrm{~m}$ of earth. Figure 3 shows how it was constructed beside an old building which could house control room, power supply, workshop and model preparations rooms.

The drive, seen in Fig. 4 during installation, consists of a $225 \mathrm{~kW}$ motor with thyristor constant speed control, eddy current coupling and reduction gear, flexibly coupled below the lower end of the rotor shaft. The $10 \mathrm{~m}$ long centrifuge arm (Fig. 5) was welded in Cambridge from four lengths of steel hollow box section and has a mass of $15 \mathrm{t}$. The top bearing plate seen in Fig. 6 secures the rotor. These last six photographs were taken in 1973, at which date the Cambridge Soil Mechanics Group had succeeded in building the centrifuge which Professor Roscoe had specified-and much credit is due to Professor Wroth who headed the group in the years after Professor Roscoe's death.

In 1974 when I rejoined the group and took responsibility for developing and operating the machine, I asked Mr Turner to design swinging platforms at each end of the arm. These allowed us to test models with free surfaces of soil and water, which swing up in flight without movement of water across the soil surface, and also allowed easy removal of swings to change the package (Fig. 7). So, I could form a small group of centrifuge workers, each of whom developed a succession of different model tests, with fast access, and therefore high utilization of the machine. ${ }^{1}$ The centrifuge always works with balanced loads, generally a model at one end (Fig. 8), and a counterweight at the other end of the arm, and both will swing up into the horizontal plane in flight.

Although our centrifuge operates on the outskirts of Cambridge, it is conveniently close to junction 13, where the new M11 motorway crosses the A1303. To handle packages of up to $1 \mathrm{t}$ mass we use one fork-lift truck at the main laboratory and another at the centrifuge and we transport the packages by van for the two miles between. This building (Fig. 9) works as an outstation with only one senior centrifuge technician, working full-time at the centrifuge and the rest of us coming out for the days on which we are involved in a test.

\section{MECHANICS OF MODELS}

Everyone working on the machine has to begin by learning about the mechanics of models. The principles have been understood for 50 years: in the first International Conference at Harvard in 1936 there is a paper by G. I. Pokrovsky who continued to be the leading figure in Soviet geotechnical centrifuge developments until his death last year; there have bccn further papers in the past three International Conferences.

The first principle concerns the question of 'weight'. In Fig. 10 a 1/100 scale model of mass $500 \mathrm{~kg}$ of soil, in flight at $r=4 \mathrm{~m}$ radius, in a centrifuge rotating at $\omega=16 \mathrm{radians} / \mathrm{s}$, has a

\footnotetext{
${ }^{1}$ To satisfy safety requirements a code of practice for safe operation has been agreed and is followed by all involved (Appendix 1).
} 


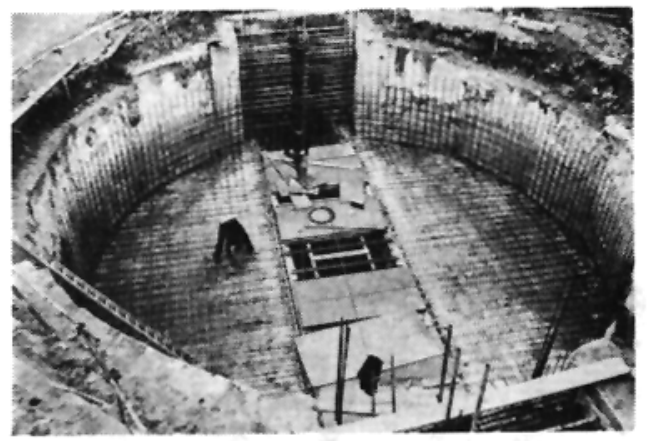

Fig. 1. Reinforced concrete structure

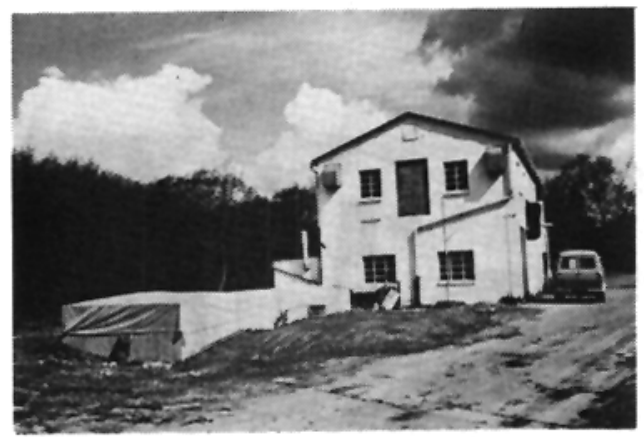

Fig. 3. The chamber buried

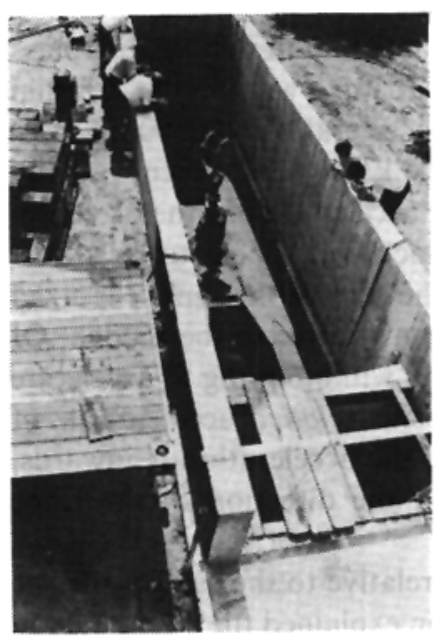

Fig. 5. Installing the balanced arm

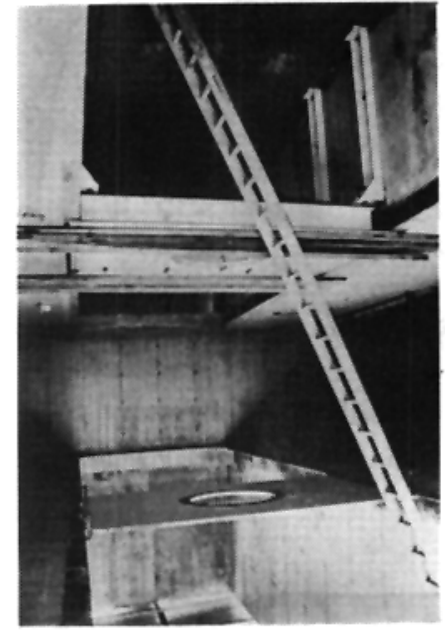

Fig. 2. Inside the chamber

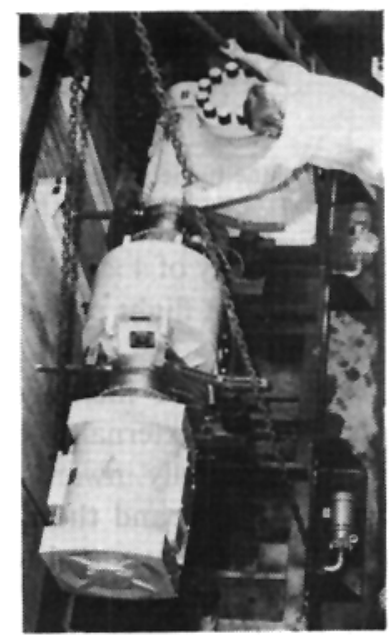

Fig. 4. Motor drive installation 


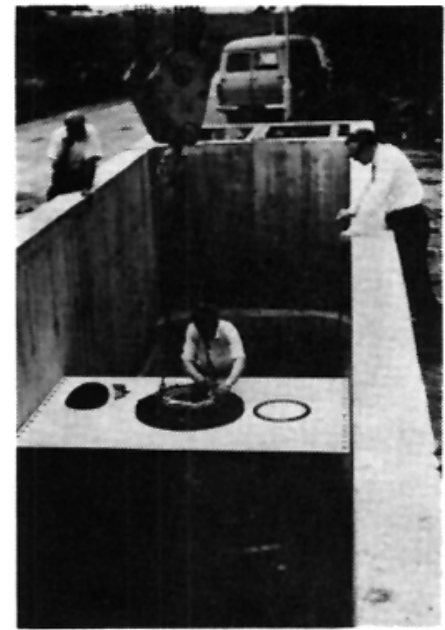

Fig. 6. The top bearing plate

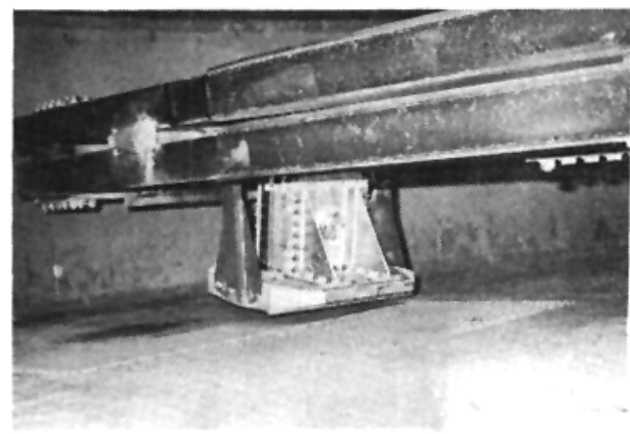

Fig. 8. The plane tunnel model package

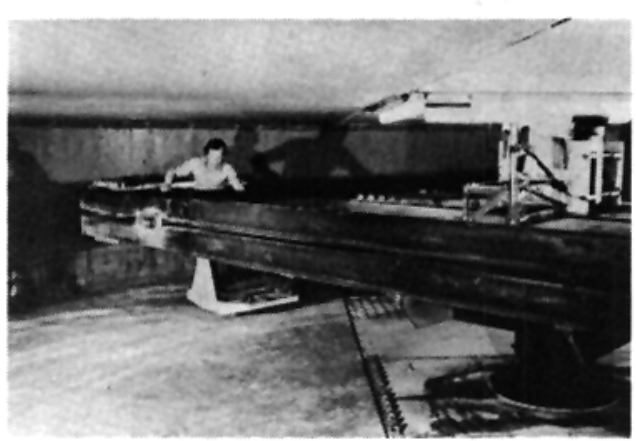

Fig. 7. The geotechnical ce.trifuge

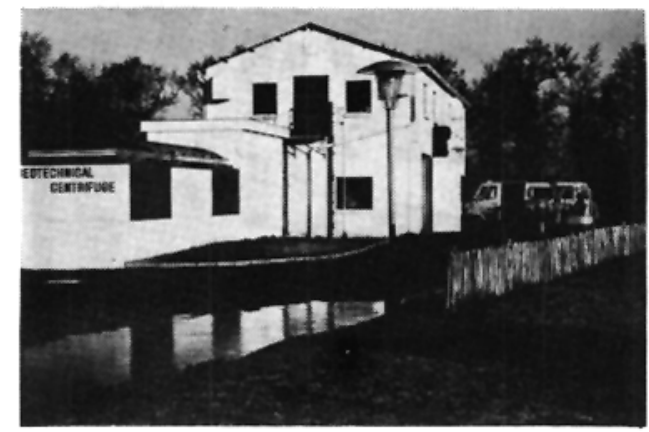

Fig. 9. A view in 1980

tangential velocity of $4 \times 16=64 \mathrm{~m} / \mathrm{s}$. Newton's laws of motion state that in pulling that mass out of its straight flight path round a curve of radius $4 \mathrm{~m}$, the centrifuge will impose a radial acceleration of $4 \times 16^{2}=4 \times 256 \simeq 1000 \mathrm{~m} / \mathrm{s}^{2}$, and to cause that acceleration the $500 \mathrm{~kg}$ mass must experience an inertial force of $500 \mathrm{~kg} \times 1000 \mathrm{~m} / \mathrm{s}^{2}=500 \mathrm{kN}=50 \mathrm{t}$ force radially inwards. Viewed externally the model appears constantly to be accelerating in the direction of the arrow, radially inwards, but in the television screen the block will appear to be at rest relative to the arm and the package that contains the model; the television camera is fixed at the centre of the arm and will rotate and not change its position relative to the model. Of course, we have to have a strong package because the block of soil will be trying to accelerate through the bottom of the package with an equal and opposite relative acceleration of $1000 \mathrm{~m} / \mathrm{s}^{2}$, which is 100 times earth's gravity. Viewed externally the acceleration is inwards, but if the frame of reference is transferred to the package, then the direction of the force field should be indicated by an arrow in the opposite direction.

The prototype of a half million tonne mass of soil seen at rest relative to the earth's surface needs good foundations if it is not to sink into the ground. Newton explained the phenomenon of terrestial masses trying to accelerate towards the centre of the earth in terms of a force of 


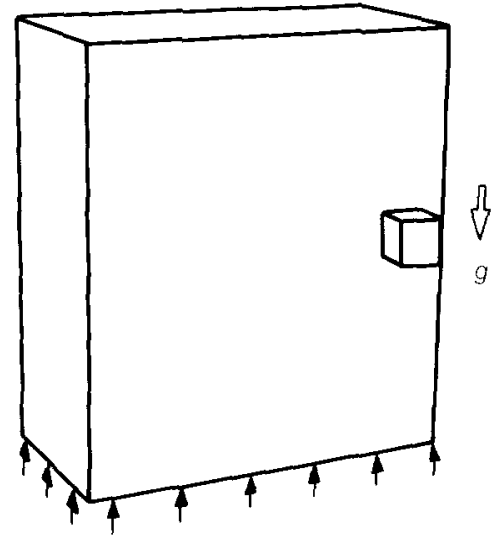

Prototype

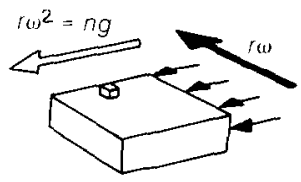

Model

Fig. 10. Weight; gravity effects in a prototype are identical to inertial effects in a centrifugal model

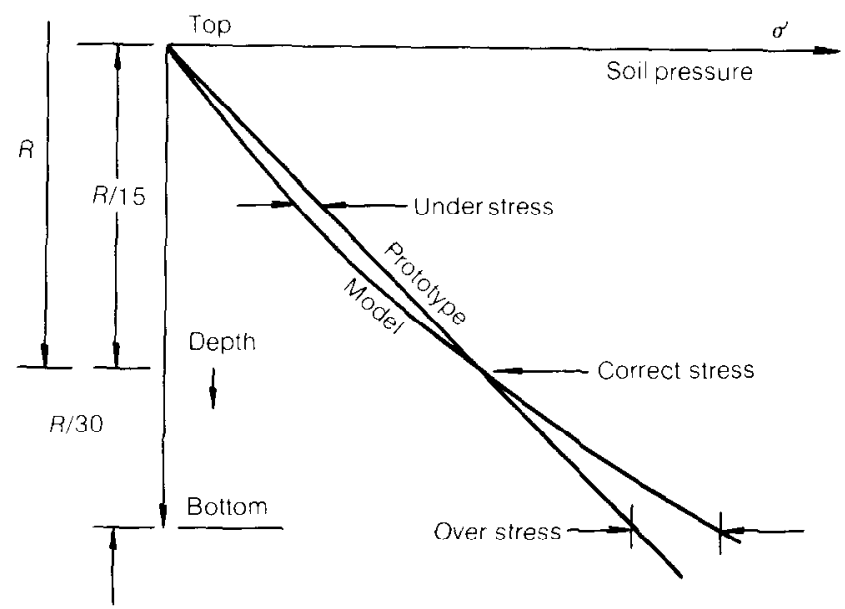

Fig. 11. Model stress error
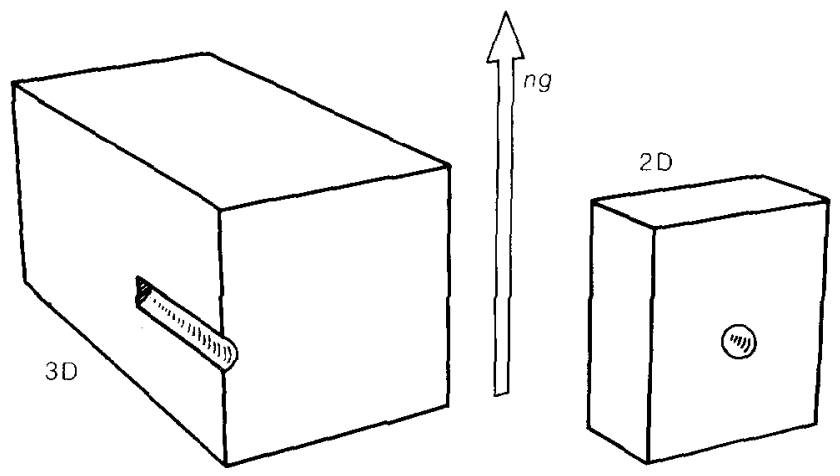

Fig. 12. Tunnels 
gravity acting on each terrestial mass. The modern relativistic explanation says that Newton's gravity force is indistinguishable from, and is identical to, an inertial force. Where Newton calculated for a space with straight geodesics Einstein's revised calculation was for a space/time reference frame warped by the presence of mass. Of course, it is not necessary to understand general relativity to understand centrifugal models, but it is worth remembering that in the view of modern physics the large prototype body in earth's gravity and the small model body in the geotechnical centrifuge experience identical physical effects. This is an excellent method because the force acts at the centre of mass of each atom and does not significantly affect the electron shells which determine all material properties other than self-weight. When a large prototype body in earth's gravity experiences pressures across its base, that force does not accelerate it at $10 \mathrm{~m} / \mathrm{s}^{2}$ out into space but simply keeps it at rest in earth's force field. The small model body in a centrifuge is at rest relative to a force field of strength typically 100 times gravity. In both cases, the upper surface of the body is unstressed, and the pressure builds up through the depth of the body.

In any centrifuge model there is a variation of acceleration in the space the model occupies. In our centrifuge, typical models subtend an arc of $\pm 0.1 \mathrm{rad}$. and extend for a radial distance of one tenth of the radius, but this does not mean there are errors in stress of $10 \%$. An integration is required to calculate the error caused by the difference between uniform acceleration in a prototype and radially varying acceleration in a centrifuge.

Model and prototype both have zero total pressure on their upper surface. Let $R$ be the effective radius of the model under test. There will be a correct pressure $\sigma_{y}$ in the $1 / n$ scale model at this radius $R$, which is at a depth $a R$ below the soil surface (Fig. 11), where $a$ is a small factor. In the prototype the corresponding depth is $n a R$ and therefore $\sigma_{V}=\rho g n a R$. In the centrifuge the slight variation of acceleration with radius requires us to integrate from the surface to depth $a R$

$$
\begin{array}{r}
\sigma_{v}=\int_{R(1-a)}^{R} \rho r \omega^{2} \mathrm{~d} r=\frac{\rho \omega^{2}}{2} R^{2} a(2-a)=\rho g n a R \\
n g / R \omega^{2}=(2-a) / 2 \quad . \quad . \quad . \quad .
\end{array}
$$

Now at all points between the soil surface and the depth $a R$ in the model there is a slight pressure deficiency. If a depth of $a R / 2$ is considered where the model pressure is only

$$
\sigma_{v}=\int_{R(1-a)}^{R(1-a / 2)} \rho r \omega^{2} \mathrm{~d} r=\frac{\rho \omega^{2}}{2} R^{2} a\left(1-\frac{3}{4} a\right)
$$

a comparison can be made with the corresponding depth in the prototype where the correct stress is $\sigma_{v}=\rho g n a R / 2$. The error in the model can be calculated as

$$
\left(\frac{\rho g n a R / 2}{\rho \omega^{2} R^{2} a\left(1-\frac{3}{4} a\right) / 2}\right)-1=\left(\frac{n g}{R \omega^{2}} \frac{4}{4-3 a}\right)-1=\left(\frac{2-a}{2} \frac{4}{4-3 a}\right)-1=\left(\frac{a}{4-3 a}\right) \text {. }
$$

For example ${ }^{2}$ if $a=1 / 15$ this error is $1 / 57$.

As depths increase below $a R$ there is overstress at all points in the model and at a depth $3 a R / 2$ the error can be calculated to be $a /(4-a)$, so for $a=1 / 15$ the error is $1 / 59$. Hence in a total model depth of $3 a R / 2=R / 10$ the magnitude of stress error is a little under $\pm 2 \%$.

A rather different type of error-the Coriolis effect-occurs whenever there is a model movement with velocity $v$ in any direction within the plane of rotation of the arm. The

\footnotetext{
${ }^{2}$ These calculations correct an earlier published version (Schofield (1976)).
} 


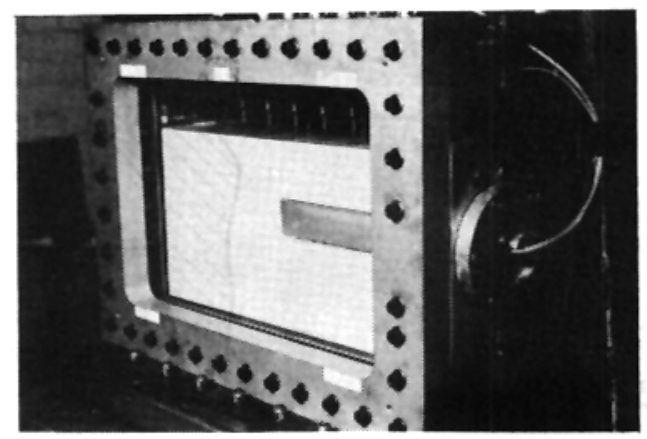

Fig. 13. The 3-D tunnel model package

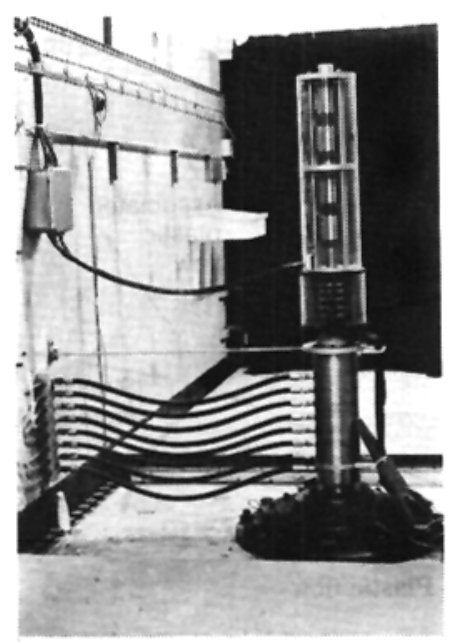

Fig. 14. Sliprings

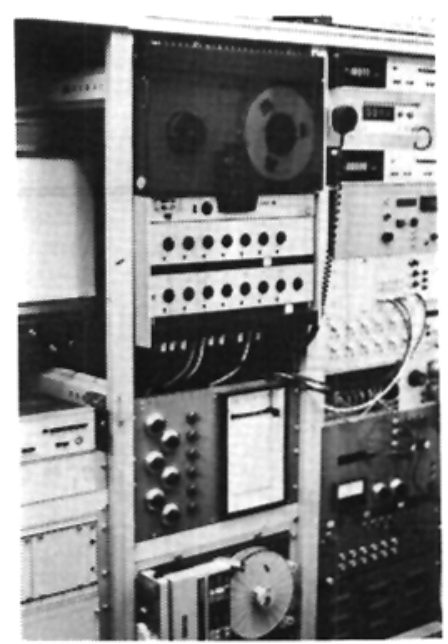

Fig. 15. Data centre

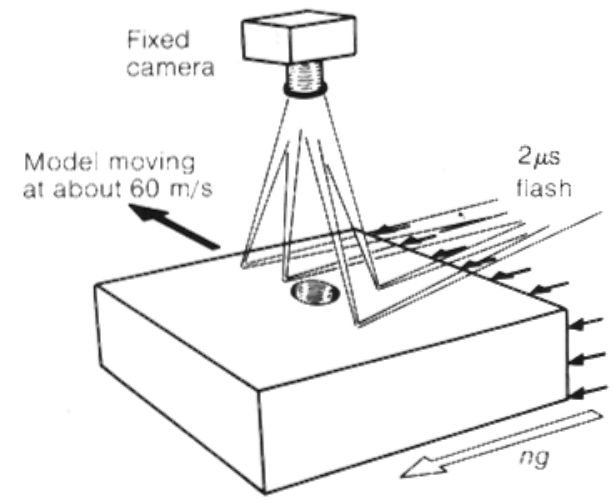

Fig. 16. Flash photograph

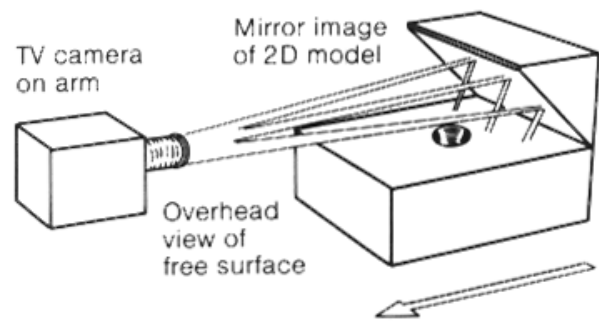

Fig. 17. Continuous C.C.T.V. 


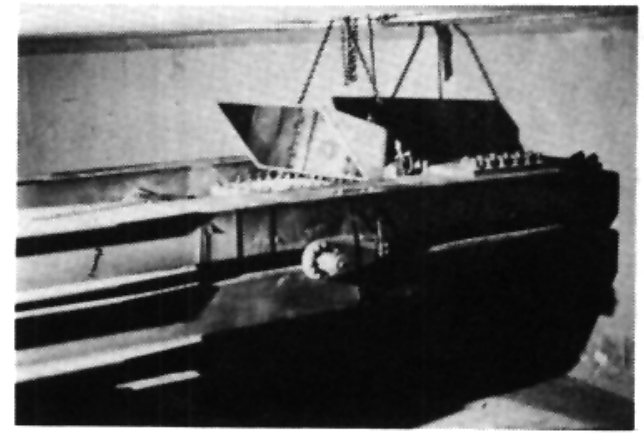

Fig. 18. The mirror

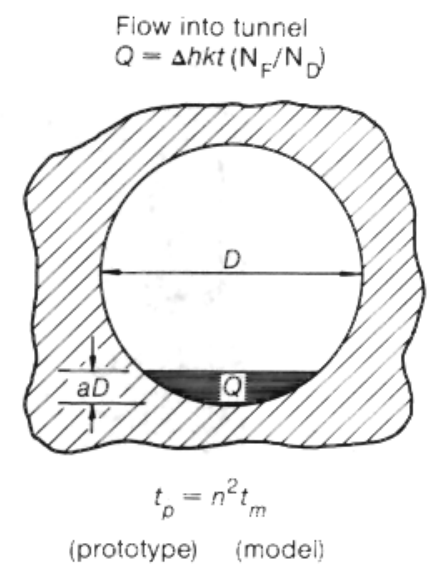

Fig. 21. Diffusion times

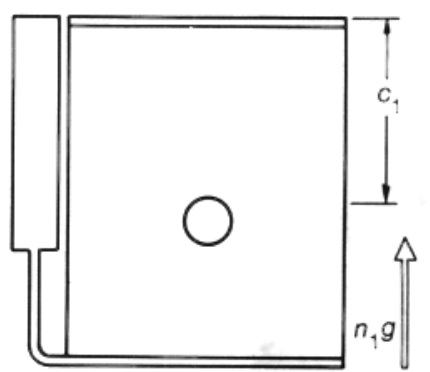

Fig. 19. Modelling of models

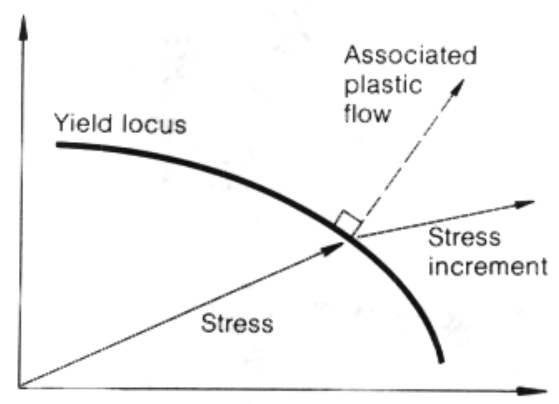

Fig. 22. Plastic flow

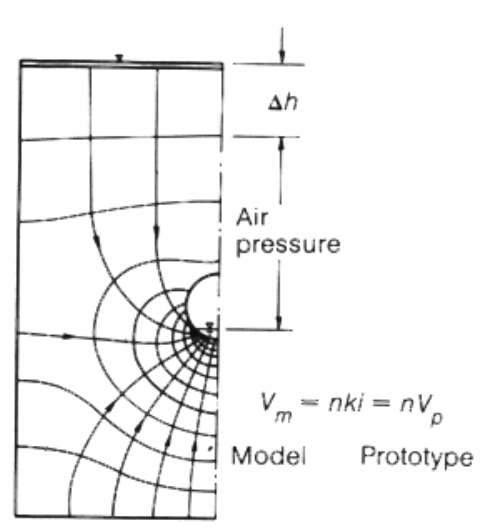

Fig. 20. Seepage

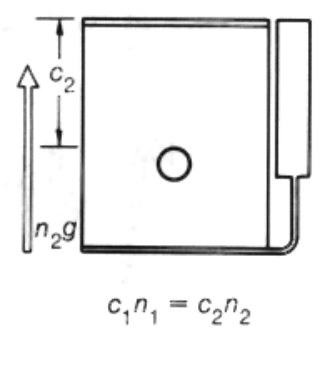

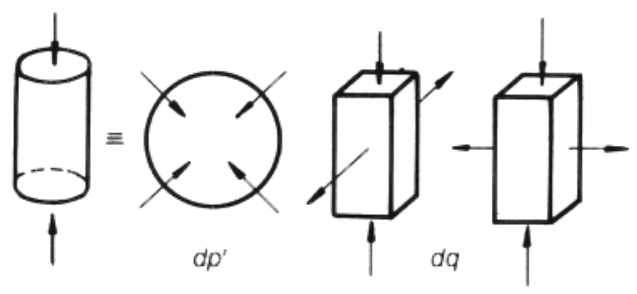
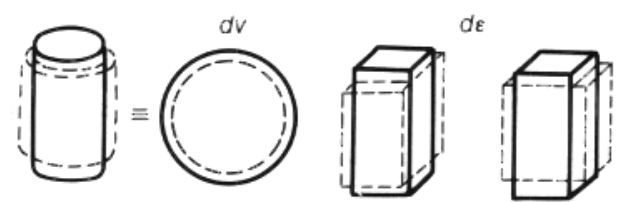

Fig. 23. 
spurious acceleration which then occurs has magnitude $2 v \omega$, where $\omega$ is the angular speed of the arm. The ratio of Coriolis acceleration to the centrifuge acceleration is

$$
\frac{\text { Coriolis acceleration }}{\text { Centrifuge acceleration }}=\frac{2 v \omega}{R \omega^{2}}=\frac{2 \times \text { velocity within model container }}{\text { velocity of model container in flight }}
$$

In our centrifuge at $n=100$ gravities and $R=4 \mathrm{~m}$, the flight velocity is $62 \mathrm{~m} / \mathrm{s}$, so for example in a seepage experiment a seepage velocity of as much as $\frac{1}{2} \mathrm{~m} / \mathrm{s}$ will involve an error of only $2 \times \frac{1}{2} / 62=1.6 \%$.

If the product of depth $\times$ acceleration is the same in model and prototype, the stresses at every corresponding point in a uniform model and prototype will differ by only a few per cent. The stresses will also be correct when the block has a hole in it (Fig. 12) uniformly supported with compressed air. As the support pressure decreases so the ground will deform until the tunnel fails. That stressing case can be considered either in two dimensions, looking at a plane section perpendicular to the tunnel, or in three dimensions, looking at a tunnel heading in section along the centre line, with a rigid lining along part of the length and an unlined heading protruding beyond it. I have not put any dimensions on Fig. 12: when I look at any model I try to see it in my mind's eye at full scale.

In the three-dimensional tunnel model package shown in Fig. 13 an $800 \mathrm{~mm}$ width of white kaolin clay is observed through a strong thick perspex face. The face cuts the tunnel on its mid-plane and to avoid loss of compressed air between the clay and the perspex the air has to be contained in a rubber bag. The rigid lining contains the bag right up to the face, but at the tunnel face the compressed air presses the bag against the soil. The clay surface carries a grid of reflecting beads which are visible in photographs. To measure the displacement above the tunnel we record the signals from the transducers.

Above the centrifuge rotor there is a slipring stack (Fig. 14) with signal channels for transducers, and hydraulic sliprings to allow flow of compressed air to the model. All outputs are recorded at the data centre (Fig. 15) in the control and observation room-either directly observed on digital volumeters, or digitized and logged on punched tape, or amplified and recorded in analogue form on a 14-track magnetic tape recorder. T'o photograph the moving model in flight (Fig. 16) a $2 \mu$ s flash is synchronized with the shutter opening of a fixed Hasselblad camera. A closed circuit television camera fixed at the centre of the arm (Fig. 17) looking along the arm provides a continuous view of the model; either an overhead view of the upper surface or the plane section of the model reflected in an inclined mirror (Fig. 18).

Many people ask what is the comparison between models and prototypes. Quite a lot of that sort of work has been done, but in detail it is difficult to be accurate because conditions in the field are rather variable. A different technique is adopted to check results. We generally repeat a test at two different scales, say $n_{1}$ and $n_{2}$ and call this the modelling of models; and we expect to see the same phenomenon repeated at the two scales if the product of length times acceleration is the same: $c_{1} n_{1}=c_{2} n_{2}$. In Fig. 19 the model is a two-dimensional tunnel model with water above and below it: we may see tunnel collapse or we may observe seepage flow if the soil is sufficiently permeable.

As long as the compressed air pressure in the tunnel balances the external water pressure, there is no flow. When the air pressure (Fig. 20) falls below the water table then an excess head $\Delta h$ causes seepage into the tunnel invert. There will be much higher hydraulic gradients into the model than into the prototype-at $100 \mathrm{~g}$ water weighs seven times the familiar weight of mercury. This is outside familiar experience. Mercury gets through holes quickly and it is not surprising that with water in a centrifuge model at $100 \mathrm{~g}$ the local seepage velocity at any point in a model is a hundred times greater than at a corresponding prototype point. The 
model seepage flow is driven by the full prototype head, but it has only the small scale path length, which is what makes the model hydraulic gradient $n i$, and hence causes the model seepage velocity to be $n$ times the prototype velocity. On occasions we have altered the permeability of model material by sieving the prototype soil and reducing the size. The permeability of the model material decreases with $d_{10}{ }^{2}$ and the quantity of water needed to be supplied to those particular models was reduced.

If there is a seepage flow into a tunnel (Fig. 21) then we will be interested to calculate how fast the water level in the tunnel will rise. The quantity $Q$ sccping into a metrc length of tunnel in time $t$ is $Q=\Delta h k t\left(N_{F} / N_{D}\right)$ which is the same for model and prototype if model and prototype both have the same permeability. In a tunnel of diameter $D$ the volume of water needed to flood the tunnel to depth $a D$ depends on the cross-sectional area which is proportional to $D^{2}$, so the time taken will be decreased with scale $n^{2}$. For example, if it takes 8 minutes at $75 \mathrm{~g}$ it will take $8 \times 75^{2}$ minutes $=1$ month in the corresponding prototype. This is a typical diffusion process; the same scale factors apply to consolidation. However, other processes scale with different factors, and model time scales always need checking with care.

A last point on mechanics of models is the importance of distinguishing the load or gencralized stress under which a model is brought into equilibrium, from the probing stress increment which then explores the yielding and possible failure of the model. This point is illustrated in Fig. 22 and is relevant here in two senses. The first sense relates to our distinction between an initial phase of model tests in which all elements are brought into equilibrium under the correct stress (this initialization may take many hours of continuous running with large clay specimens) and the test proper in which that equilibrium is perturbed by application of a stress increment (in some cases the test loading may only take a fraction of a second). The second sense relates to the distinction between the theories of elasticity and plasticity. In the theory of elasticity, the vector of generalized stress increment is proportional to the strain increment-associated flow is independent of stress. Elastic theory does not fit soil well even in non-linear forms, and a better theory is plasticity where a specimen or system yields with the vector of stress associated with the plastic flow. To get the correct deformation and flow in geotechnical models every element has both to be brought into equilibrium under the correct stress and also probed with the correct stress increment.

\section{REMOULDED SOIL BFHAVIOUR}

Theory of plasticity is of course central not only to the analysis of centrifuge models, but also to behaviour of remoulded soil in critical state soil mechanics. The strength and stiffness of remoulded soil depends on its density and effective pressure, and when it yields, its hardening depends on plastic volume change. In this section I will try to explain this in a new way, paying particular attention to what is said about fracture in critical state soil mechanics.

A general stress increment (Fig. 23) on a specimen of linear isotropic elastic material can be resolved into an effective spherical increment, $\mathrm{d} p^{\prime}=\left(\mathrm{d} \sigma_{1}{ }^{\prime}+\mathrm{d} \sigma_{2}{ }^{\prime}+\mathrm{d} \sigma_{3}{ }^{\prime}\right) / 3$, and a generalized deviatoric increment, $\mathrm{d} q=\left(\mathrm{d} \sigma_{1}{ }^{\prime}-\mathrm{d} \sigma_{3}{ }^{\prime}\right)$. In soil mechanics one defines a positive volume change $\mathrm{d} v$ to correspond with a positive spherical pressure increase. A positive deviatoric stress increment causes a positive distortion increment $\mathrm{d} \varepsilon$ and vice versa. In a linear isotropic elastic material there cannot be a connection between shear stress and dilation because if a clockwise shear stress produced dilation then conversely an anticlockwise shear stress would have to produce compression.

The elastic model cannot therefore match the progress of rupture, during which either a clockwise or an anticlockwise shearing both produce dilation on the rupture plane. Observations at peak strength of soil fit Fig. 24, which follows Hvorslev's approach and considers a 

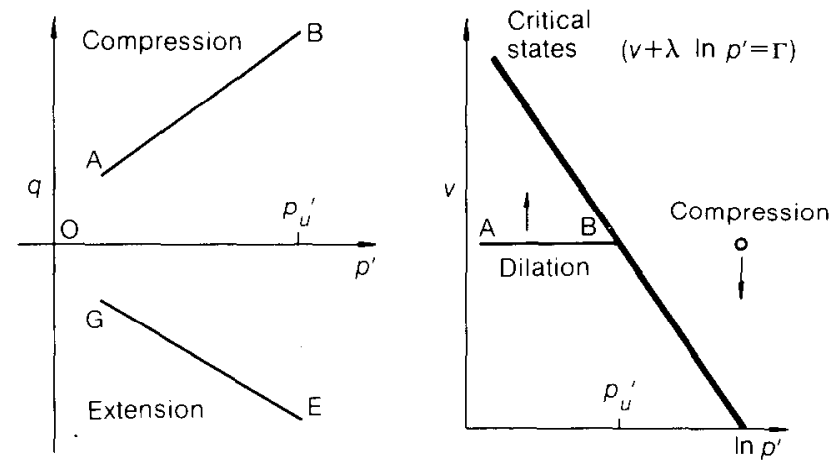

Fig. 24. Coulomb rupture

set of specimens all at the same specific volume $v$ at the moment of failure during drained triaxial tests. $^{3}$ For such specimens the rate of dilation decreases as effective pressure increases until a critical pressure $p_{u}{ }^{\prime}$ is reached after which Coulomb ruplure planes are not observed. At all pressures higher than the critical pressure for the specific volume the behaviour changes to plastic work hardening with yielding and plastic compression. Experiments show that the variation of critical pressure with specific volume follows a fairly well-defined line of critical states. Soil in states of pressure and specific volume less than critical states fails with welldefined rupture planes (and after reaching peak strengths fitting lines $A B$ and GF the dilating soil on the rupture planes then softens to critical state plane strengths fitting lines $O B$ and $O E$ ). This class of behaviour is very familiar to geotechnical engineers, but although it is 18 years now since behaviour on the other side of the critical state line was successfully modelled the majority of geotechnical engineers remain unfamiliar with the way in which, by application of theory of plasticity, it proved possible to create a valid constitutive model called cam-clay which fits many data of loading and yielding of triaxial test samples in states of pressure and specific volume higher than critical states.

The original cam-clay model (Fig. 25) was synthesized from two basic equations. The first says that if yielding obeys the stable associated plastic flow rule then the product of the plastic flow increment $(\mathrm{d} v, \mathrm{~d} \varepsilon)$ and any stress increment $\left(\mathrm{d} p^{\prime}, \mathrm{d} q\right)$ outward directed from the yield locus is positive or zero-the zero applies to stress increments directed along the tangent to the yield locus. The second equation says that when yielding occurs the work is purely frictional and the vector product of stress times plastic flow increment is equal to frictional work ( $M$ is a generalized coefficient of friction) times $p^{\prime}$ the pressure, times $\mathrm{d} \varepsilon$ the distortion increment. For details of definitions of, for example, the sign of $\mathrm{d} v$ one must turn to Critical state soil mechanics (Schofield \& Wroth, 1974); but in simple terms after eliminating the dilatancy rate $\mathrm{d} v / \mathrm{d} \varepsilon$ between these equations a single differential equation is left which when integrated predicts the form of the cam-clay yield curve (CD in Fig. 25). The specimens we are considering on this line $C D$ are all on one elastic compression line. Curve $\mathrm{CD}$ allows stress to extend a certain distance beyond the critical state line but there is a limitwhen $q=0$ the pressure cannot extend further than $\mathrm{D}$, if the material is to remain stable. If there were soil in states beyond D it would be unstable, and it is generally supposed that dangerous flow slides occur when soil gets in such unstable states.

\footnotetext{
${ }^{3}$ Specific volume $v=1+e$ is volume of space occupied by unit volume of solids: in a triaxial test $q=\left(\sigma_{1}{ }^{\prime}-\sigma_{r}{ }^{\prime}\right)$ is deviator stress difference of longitudinal and radial stress, $p^{\prime}=\left(\sigma_{1}{ }^{\prime}+2 \sigma_{\mathrm{r}}{ }^{\prime}\right) / 3$ is effective mean normal pressure average over all three principal stress components. For a detailed example see Fig. 8.13 of Critical state soil mechanics (Schofield \& Wroth, 1974) which presented data of failure of tests of Wcald clay, after Parry.
} 


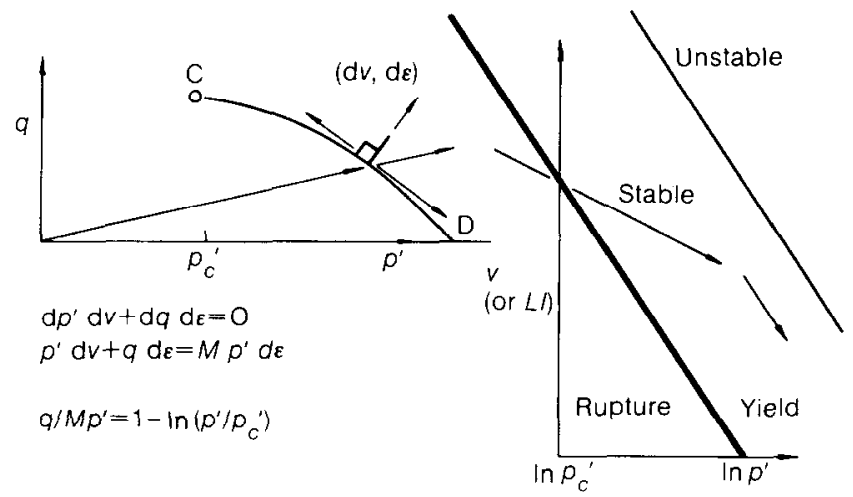

Fig. 25. Cam-clay yielding

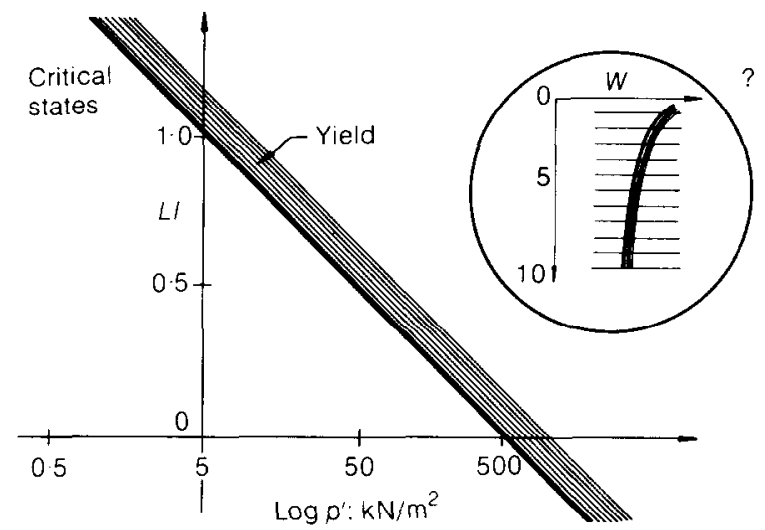

Fig. 26. Variation of $p_{u^{\prime}}$ with $L I$

In Critical state soil mechanics it was shown that it is possible to generalize the density or specific volume axis by converting to a liquidity basis; Fig. 26 shows the critical state line on axes of liquidity versus $\log p^{\prime}$, but over a much larger range of pressure than Fig. 25 . Figure 26 follows a figure from Critical state soil mechanics (Fig. 6.14) which shows the critical pressure to be about $5 \mathrm{kN} / \mathrm{m}^{2}$ at the liquid limit and $500 \mathrm{kN} / \mathrm{m}^{2}$ at the plastic limit. ${ }^{4}$ These numbers are subject to discussion in detail. Both the 5 and $500 \mathrm{kN} / \mathrm{m}^{2}$ and their ratio of 100 should be thought of as order-of-magnitude estimates for the purpose of this lecture. At this scale, the band of cam-clay yielding is quite narrow, and corresponds to only about 0*16 liquidity range. Figure 26 also shows a more familiar figure with liquid and plastic limits of soil indicated throughout the depth of a deposit. Within the circle, the profile indicates a soil of uniform properties to depths of 5 and $10 \mathrm{~m}$. If we make an assumption about $K_{0}$ then we can sketch the band of expected normal consolidation or yielding states with depth. In sketching this curve I made the questionable assumption that for this soil deposit the value of $K_{0}=1$. Changing the assumption would change the position of the curve but does not

\footnotetext{
${ }^{4}$ At this critical pressure of $500 \mathrm{kN} / \mathrm{m}^{2}$ soil at its plastic limit would shear at constant volume in a drained shear test at constant $p^{\prime}$, and it will be secn later that this $500 \mathrm{kN} / \mathrm{m}^{2}$ is ten or more times more than the effective pressure or suction in the plastic limit thread when it is made to crumble in the index test.
} 


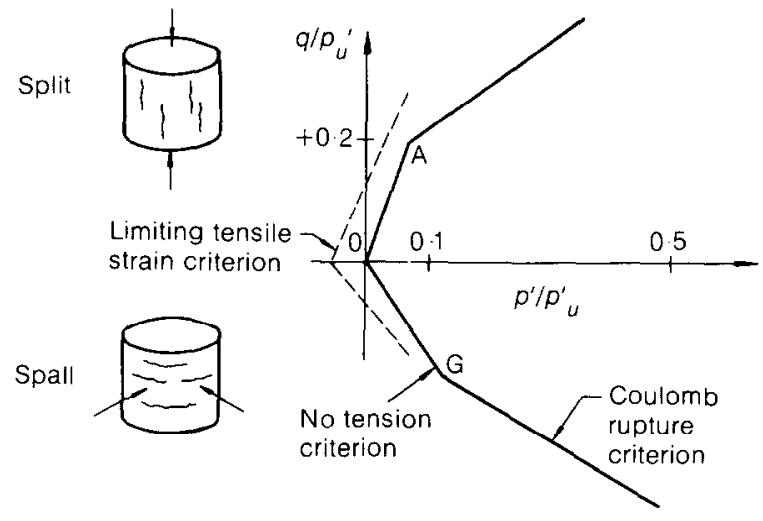

Fig. 27. Tensile fracture

change the width of the band. One of the tests I will describe is on a sample of Champlain Sea clay from a site where the clay at $5 \mathrm{~m}$ depth was at 0.75 liquidity-well into the region that becomes unstable when remoulded. In order to bring the remoulded soil into the stable yielding region either the water content must change, which will require time for consolidation, or the effective stress must fall, which will mean substantial pore water pressure generation. Notice how narrow the band is of liquidity corresponding to cam-clay-only about $0 \cdot 16$. Models will also be tested in the region of lower liquidity to the left of the critical state line and this raises the question of what the width of the band is in which one can expect to observe Coulomb rupture behaviour. The answer is about 0.50 .

In Critical state soil mechanics we suggested adoption of a no-tension criterion at the low effective pressure. If one looks at the data of Weald clay one can say that the lower end to Coulomb rupture and the change to tensile fracture, is in the vicinity of $p^{\prime} \mid p_{u}=0 \cdot 1$, as indicated by points $A$ and $G$ respectively in compression and extension in Fig. 27. This position may need to be adjusted after present research is finished-perhaps a tensile strain criterion will provide a better fit to data for splitting in compression and spalling in extension-but for this lecture let me stick to the intersection of Coulomb and no-tension criterion to give a working limit $p^{\prime} ! p_{u}=0 \cdot 1$ at the low end of the rupture band, averaging extension and compression.

Considering a set of drained test samples in Fig. 28 all reaching limiting states at one value of density or liquidity, if we test each sample at constant $p^{\prime}$ with increasing or decreasing deviator stress, we will find limits such as these to elastic behaviour. The lines OA and OG indicate fracture, AB and GE indicate Hvorslev's Coulomb rupture planes, and BD and ED indicate cam-clay yielding. The figure is drawn with $p^{\prime} / p_{u}{ }^{\prime}=1$ at the critical state and, of course, $p_{u}{ }^{\prime}$ is a function of liquidity. When this is replotted on a logarithmic base, if $p_{u}{ }^{\prime}=$ $500 \mathrm{kN} / \mathrm{m}^{2}$ then the high end of the yield band ${ }^{5}$ is $500 \times 1.9=950 \mathrm{kN} / \mathrm{m}^{2}$ and the low end of the rupture band is $500 \times 0 \cdot 1=50 \mathrm{kN} / \mathrm{m}^{2}$. The logarithmic plot will spread out the low pressure region. The width of the rupture band will be one $\log$ cycle, from $0 \cdot 1$ to $1 \cdot 0$.

In Fig. 28 the line limits OABDEGO suggest the simple division of behaviour at limiting states into three different classes of failure-fracture, rupture and yield. In Critical state soil mechanics we proposed drawing a pair of lines $\mathrm{OB}$ and $\mathrm{OE}$, corresponding to $\phi=\phi_{\mathrm{c}}{ }^{\prime}$ for the

\footnotetext{
${ }^{5}$ Figure 28 is drawn for the case of Weald clay and for other soil constants there could be a change in the value of 1.9 at point $D$.
} 


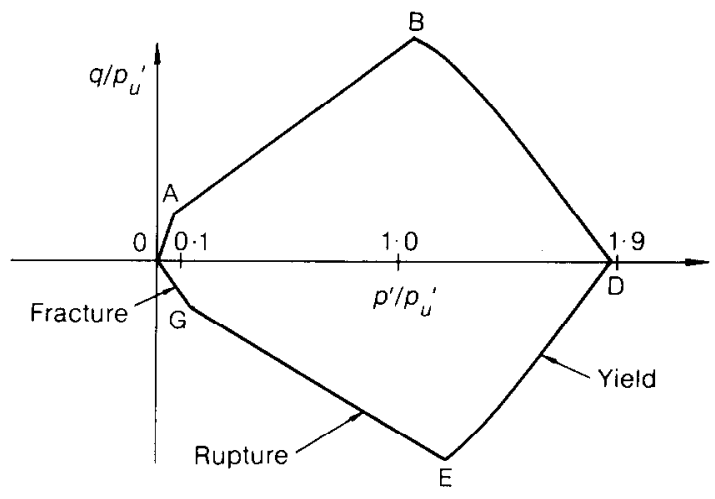

Fig. 28. Limiting states

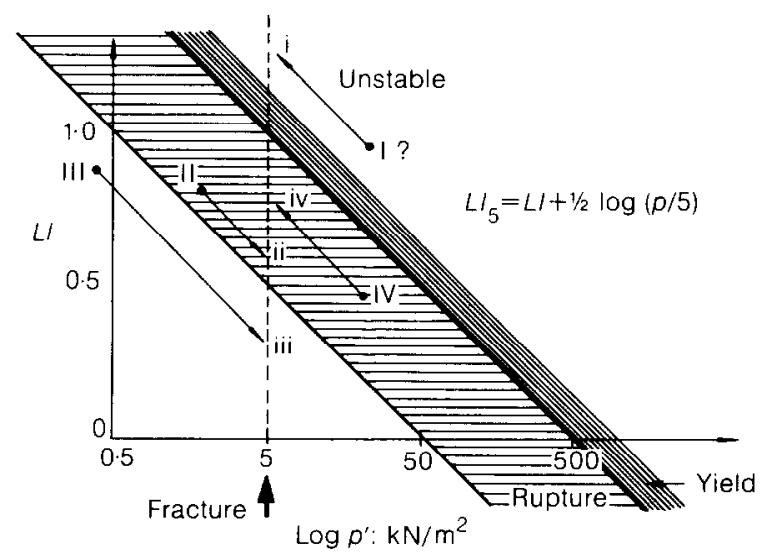

Fig. 29. Equivalent liquidity: $L I_{5}$

strength of fully softened saturated soil in the triaxial compression test, and we suggested to our students that in analysis of the fully softened long-term condition it was prudent to calculate for zero cohesion, $c=.0$. This seemed conservative since $O B$ and $O E$ lie within $O A$ and $O G$, but as we will see later it led us to neglect detailed consideration of fracture. However, leaving that question aside for the present, the next figure will display the significance of these numbers $0 \cdot 1,1.0$ and 1.9 on the $p^{\prime} / p_{u}{ }^{\prime}$ axis of Fig. 28.

In Fig. 29 the map of remoulded soil behaviour has axes of liquidity against $\log p^{\prime}$. Following Critical state soil mechanics we take there to be a hundred-fold increase in pressure from the liquid limit critical state $p_{u}{ }^{\prime}$ to the plastic limit critical state $p_{u}{ }^{\prime}$ which is two log cycles, so the rupture band has half the width of $P I$ and will intersect the line $p^{\prime}=5 \mathrm{kN} / \mathrm{m}^{2}$ at $L I=0.5$. This intersection is a consequence of putting the lower limit of Coulomb ruplure a little arbitrarily at $\mathrm{p}^{\prime} \mid p_{u}{ }^{\prime}=0 \cdot 1$. I will be discussing tests with soil in states indicated by Roman numerals I, II, III, IV. In order to identify the band of behaviour in which these states lie, let me simply project in the direction of the arrows parallel to the critical state line and define the position of various states, I, II, III and IV by what I will call their 'equivalent liquidities', i, ii, iii and iv. 


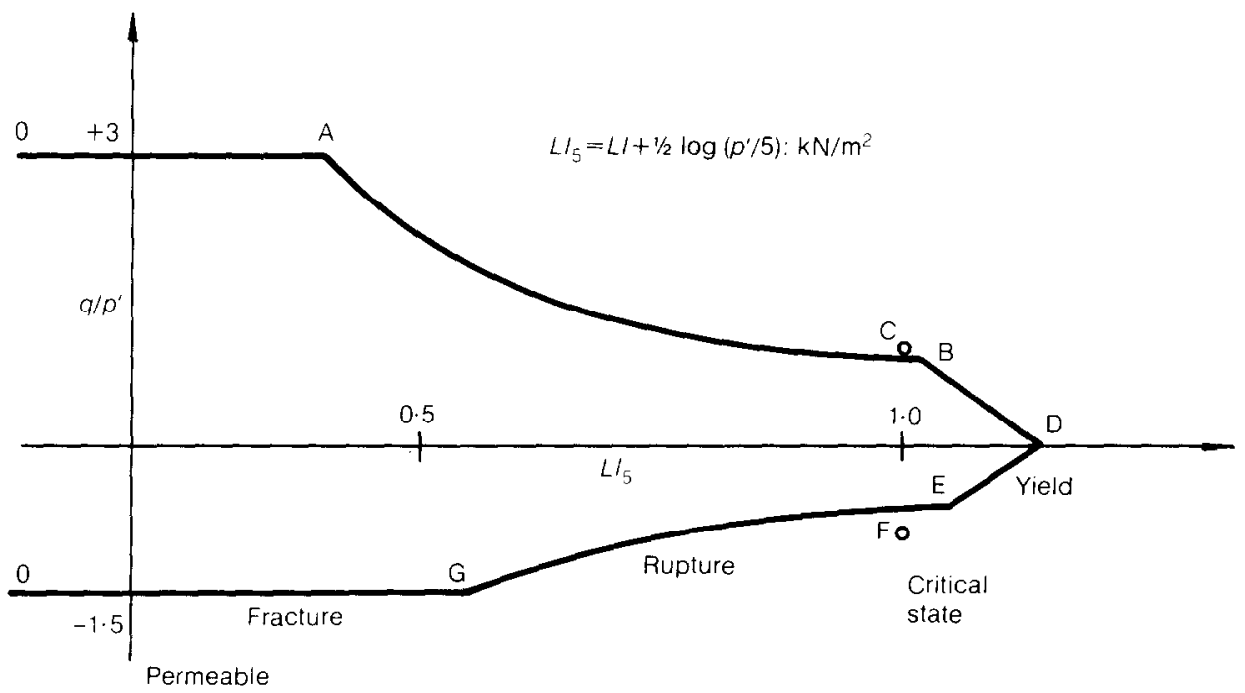

Fig. 30. Liquidity and behaviour

A specimen of soil at IV, with effective pressure $30 \mathrm{kN} / \mathrm{m}^{2}$ and 0.5 liquidity, projects to an equivalent liquidity at iv. The correction for calculating equivalent liquidity involves

$$
\left(\log p^{\prime}-\log 5\right) /(\log 500-\log 5)=\log \left(p^{\prime} / 5\right) / \log 100=\log \left(p^{\prime} / 5\right) / 2
$$

The equivalent liquidity to IV is $L I_{5}$ equals liquidity as actually found in the ground plus a correction for stress which is $\frac{1}{2} \log (30 / 5)=\frac{1}{2} \log 6$ which is about $0 \cdot 4$; the state at IV is equivalent to a $0.5+0.4=0.9$ equivalent liquidity. Note that a specimen at III under very light stress has a negative stress correction bringing its equivalent liquidity below 0.5 -this is in the band of fracture behaviour. I have.already spoken of a test of Champlain Sea clay which if remoulded would be at liquidity and pressure mapped by point I; it cannot stay there when remoulded, and in a rapid undrained failure develops positive pore pressure. Now stress ratios $\left(q / p^{\prime}\right)$ on a section of this map along the dashed line i, ii, iii, iv will be considered.

Figure 30 shows the section of the map at constant $p^{\prime}:$ stress ratios will increase as equivalent liquidity falls. The limits are replotted-once again using soil data for Weald clay from Critical state soil mechanics. In the high equivalent liquidity range, stress ratio increases linearly as liquidity of original cam-clay falls. The Hvorslev surface gives the rupture limits which allow higher stress ratios as one approaches lower values of $p^{\prime} \mid p_{u}{ }^{\prime}$, but at the no-tension limits, $q / p^{\prime}=3$ in compression and -1.5 in extension. There is a general increase of limiting stress ratio as equivalent liquidity falls, but this is not a continuous change because there is a change of limiting behaviour from continuous yield, to discrete rupture, to fracture of stiff fissured soil at equivalent liquidity below 0.5 .

This figure shows that equivalent liquidity can play a similar role to corrected relative density or corrected SPT value, in characterizing the state of ground under pressure. In calculating $L I_{5}=L I+\frac{1}{2} \log p^{\prime} / 5$, the first coefficient of $\frac{1}{2}$ relates to the logarithm of the ratio effective critical pressure at the liquid and plastic limit assumed to be 100 , and the second coefficient 5 relates to the effective critical pressure at the liquid limit in $\mathrm{kN} / \mathrm{m}^{2}$. If, for example, $I$ had assumed the ratio to be 70 and the pressure to be $3 \mathrm{kN} / \mathrm{m}^{2}$ then the calculation 


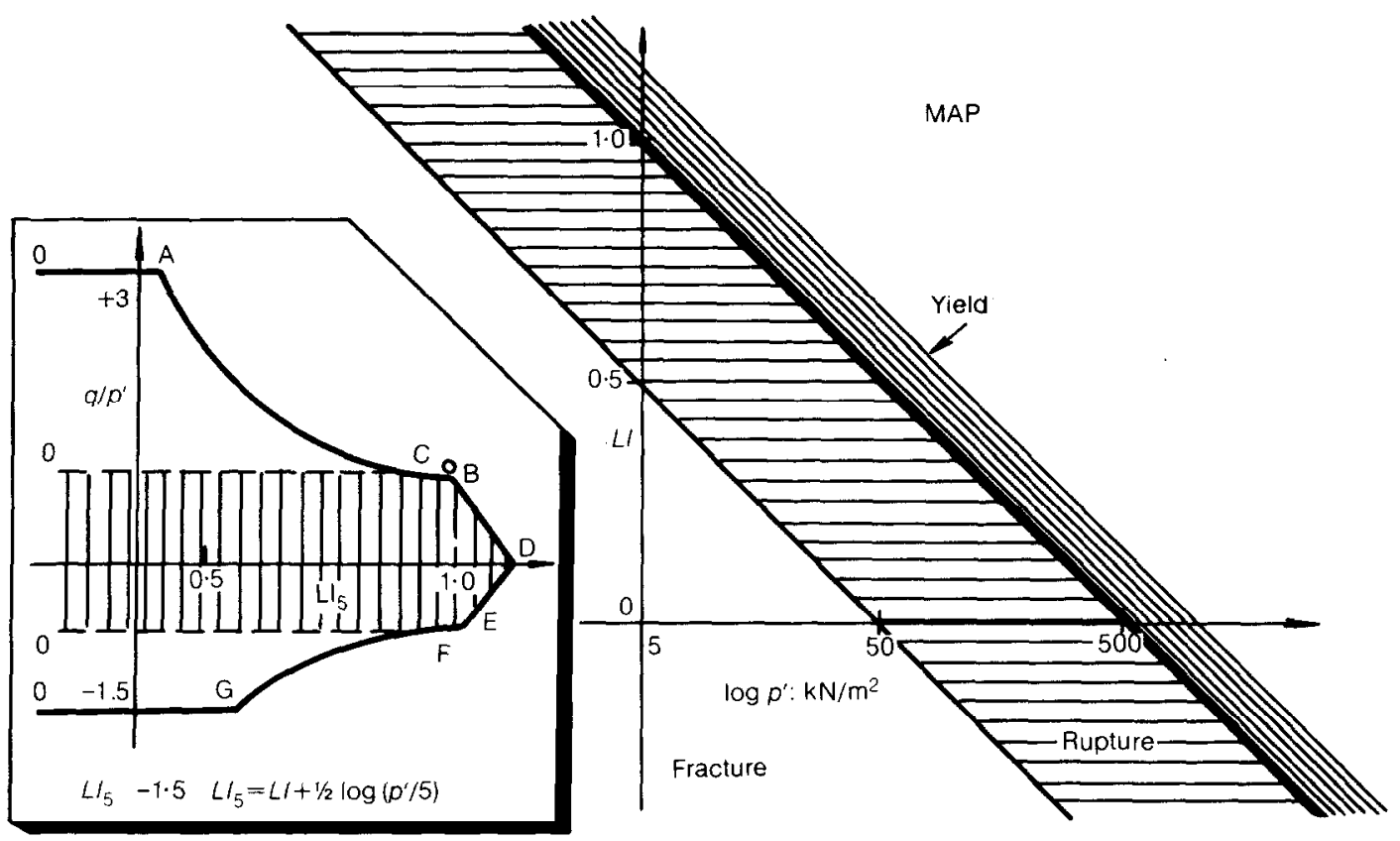

Fig. 31. Remoulded soil behaviour

would simply have become $L I_{5}=L I+\left(\log p^{\prime} / 3\right) /(\log 70)$. My concern here is not to define these coefficients closely but to explain a principle.

In summary, Fig. 31 is a map of soil behaviour with the section at constant $p^{\prime}$, which I hope explains my confidence in using remoulded soil to make models. All soil behaviour depends in a major way on the density and the effective pressure. Twenty-five years ago when I asked Roscoe about the strength of soil he gave me his translation of Hvorslev's thesis, and explained that the strength of soil depended on the voids ratio in the region of failure and the normal pressure on the plane of failure. This map is a simple development of that view. The boundaries between these bands of different behaviour are only slightly different in compression and extension. In general, the combination of density and pressure that determines whether soil will fracture, rupture or yield can be expressed by the equivalent liquidity. In a broad sense correct behaviour of models will occur if all points in a model are at correct equivalent liquidity. (We can perhaps extend the range of our modelling scales by a factor of ten, if we work with model soil with the moisture content higher than prototype soil by an amount equal to half the plasticity index, which means we can use a $100 \mathrm{~g}$ centrifuge and make models at a scale of $1: 1000$.) If a more detailed view is taken then the boundaries of these bands will depend on the direction of the stress path and the centrifuge model should follow the correct path. This view of soil behaviour is an oversimplification. In order to correct errors and improve our teaching, experience of a variety of boundary value problems is needed. The first set of models I will discuss are in states near critical states: after them I will discuss problems with soil further from critical equivalent liquidity states.

TUNNELS IN SOFT GROUND (MAIR, R. J. (1979), TAYLOR, R. N. (1979))

Tunnels in soft ground provide an example in which soil at high equivalent liquidity fails in an undrained fashion, and calculations by the theory of plasticity can be accurately fitted 

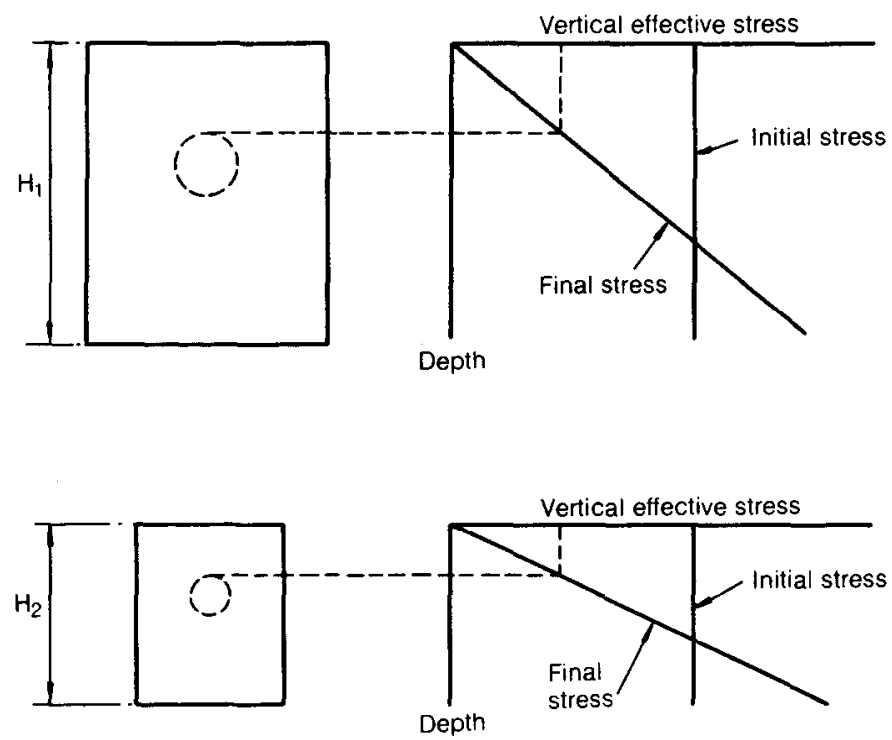

Fig. 32. Model stress history

to model test data. In these recent tests, considerable care was taken to control ground conditions. For correct modelling of models the soil at corresponding points should have identical stress history. In Fig. 32 we consider two models at 1/75 and 1/125 scale. Both blocks of soil are compressed initially to $171 \mathrm{kN} / \mathrm{m}^{2}$ in a press on the laboratory floor for over a week. Then, both blocks are allowed to swell back for over 10 hours in centrifuge flight. The smaller model has a higher stress gradient in it, and this produces exactly the same overconsolidation ratio in the soil at the tunnel crown in both models. At that stage the centrifuge is stopped, the tunnel cut and fitted with compressed air supply, the centrifuge restarted, and the air pressure increased to balance the overburden pressure. If a typical cube of soil in the tunnel crown is considered, in the two models the initial pressure is the same, the pressure after swelling is the same, the cycle of unloading and reloading when the tunnel was cut is the same. These tests do not represent a specific prototype, but do achieve close similarity of models at different scales.

When the centrifuge was in flight and the working stress conditions were established, then the test perturbation was applied. It was simply reduction of tunnel pressure with observation of deformations and pore pressures during tunnel failure. Figure 33 shows one of many model tunnels after failure. We can see that originally straight lines of silver beads have been distorted. We observe yielding below the tunnel invert, and Coulomb rupture beside the tunnel.

From close study of actual failures the small group of research workers were able to generate new kinematically admissible collapse mechanisms and new statically admissible stress distributions which are shown in Fig. 34. These new theories allow calculations of collapse loads provided the appropriate shear strength is used. The appropriate shear strength for clay with this stress history is that found in plane strain extension. For that applied stress path the centrifuge research workers could find a value of strength from theses written by previous research workers in our laboratory.

At various ratios of cover C to diameter D Fig. 35 shows the ratios of tunnel pressure $\sigma_{T}$ to shear strength $c_{u}$ at collapse. The calculated values of upper and lower bounds to collapse 


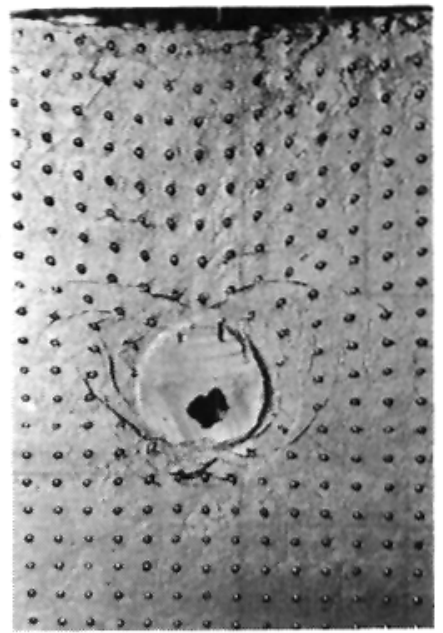

Fig. 33. Plane tunnel failure
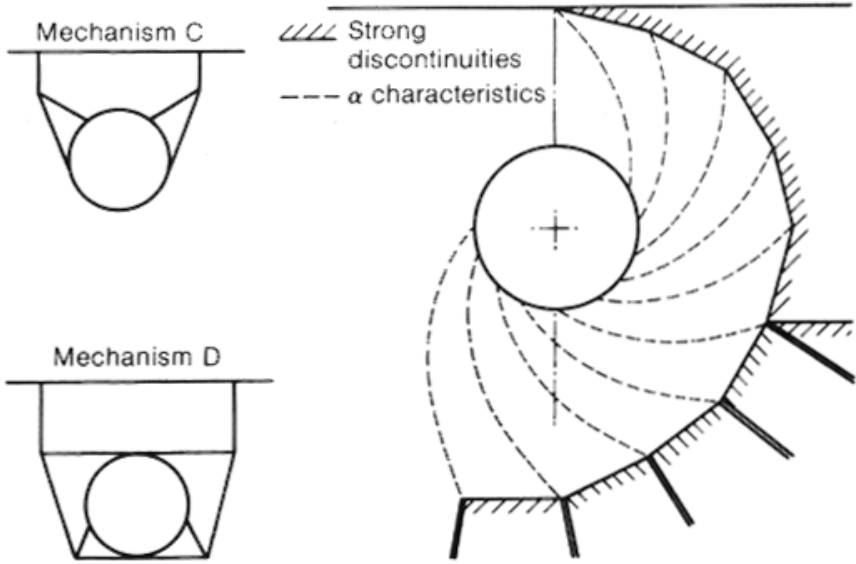

Fig. 34. Plastic mechanisms and stress distributions

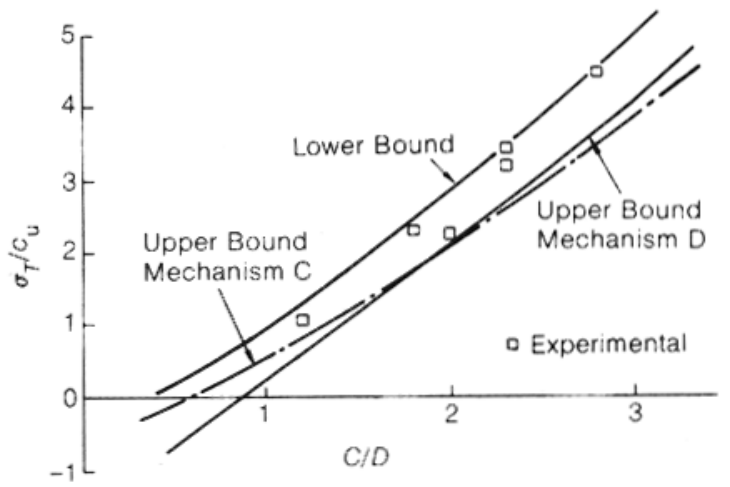

Fig. 35. Plane tunnel collapse data 


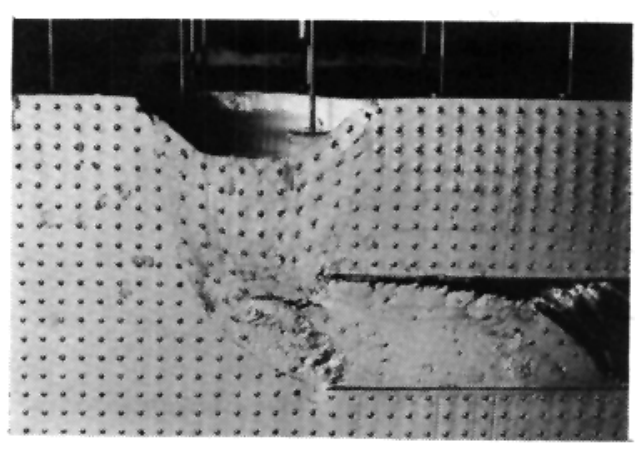

Fig. 36. 3-D tunnel: $P / D=0$

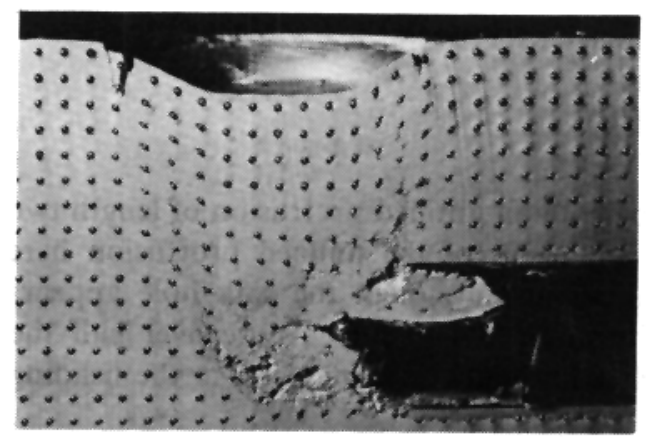

Fig. 38. 3-D tunnel: $P / D=1$

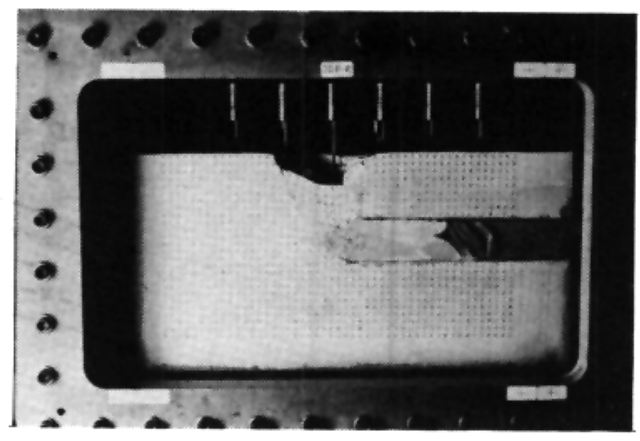

Fig. 37. 3-D tunnel: $\mathbf{P} / \mathbf{D}=\frac{1}{2}$

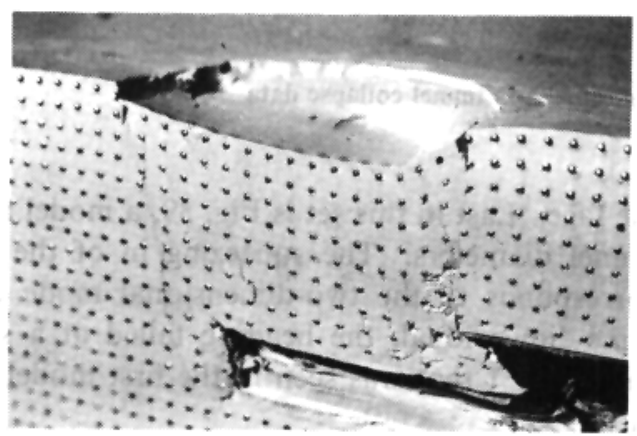

Fig. 39. 3-D tunnel: $\mathbf{P} / \mathbf{D}=\mathbf{2}$

loads are seen as closely fitting the observed data. The research workers had at that stage produced a high quality solution to the plane problem of collapse of an infinitely long unlined tunnel. Unfortunately, this idealization does not closely describe tunnel headings.

In practice, the tunnel is rigidly lined as soon as it is excavated; the compressed air supports the tunnel face, and when air pressure falls there is a three-dimensional failure. This problem is difficult to analyse and our research workers have only got one calculation of an upper bound mechanism for the three-dimensional problem. To make matters more difficult, in some cases there is an unsupported or poorly supported short length of heading protruding beyond the rigid lining. We have no upper or lower bound calculations for the case of an unsupported protrusion. However the research workers were able to test a series of threedimensional models such as this with various protrusions and observe collapse. When the protrusion is zero as in Fig. 36, the original face rotates and is forced down the tunnel by the descending plug of soil above the tunnel face. Note the original positions of silver beads undisturbed behind the rotating face. This heading stability ratio, at failure, was $N_{T c}=7 \cdot 1$.

The next model heading (Fig. 37) had an unlined protrusion of half a diameter and the stability ratio at failure fell to $6 \cdot 1$. You can see at the tunnel face that the roof and sides came in and trapped a short portion of the rubber bag. All these models have $60 \mathrm{~mm}$ diameter, so at $118 \mathrm{~g}$ they correspond to a $7 \mathrm{~m}$ prototype tunnel below $10 \mathrm{~m}$ of soil cover. The next model, in Fig. 38, had a longer unlined protrusion, of length equal to one tunnel diameter, and failed with a still lower stability ratio of 5.3. The plastic flow mechanism is complex, with clay squeezing in to trap the rubber bag in the unlined heading, but still showing rotation of 


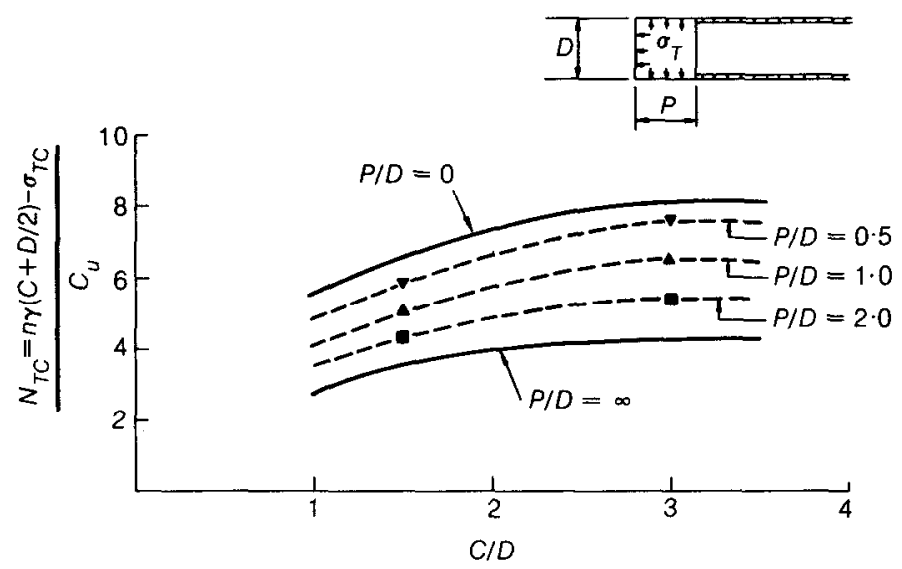

Fig. 40. 3-D tunnel collapse data

the face. Last in this set is Fig. 39, a model heading with an unlined protrusion of length two tunnel diameters. The squeezing in of the roof and walls of the unlined protrusion here corresponds to the two-dimensional mode of failure, and although the sink hole appears three-dimensional, the heading failed at a stability number 4.4 , only a little over half the value of $7 \cdot 1$ that was seen in the first model which was rigidly lined right up to the heading face.

In Fig. 40 stability ratios for tunnel headings with various protrusion ratios $\mathrm{P} / \mathrm{D}$ were plotted against various cover to diameter ratios $\mathrm{C} / \mathrm{D}$. The bottom curve is the least stable case- the infinitely long unlined tunnel. The upper curve is the face with no protrusion. Between these curves are experimental points corresponding to various protrusions: these experimental results show the stability ratio of 6 corresponding to no protrusion at $\mathrm{C} / \mathrm{D} \simeq 1$ (shallow cover), and to a protrusion of one tunnel diameter at $P / D \simeq 1$ (deeper cover). This figure gives an accurate answer to a problem of plasticity which is too complex to be solved by any presently available calculations.

While the safety of the heading is the first consideration, the damage due to surface settlement is almost as important. Movement of ground onto the tunnel shield is well modelled in the two-dimensional idealization. Figure 41 has data for the settlement trough-the shape is well known from work of Peck and others. The data are of three models: two at $125 \mathrm{~g}$ and one at $75 \mathrm{~g}$.

All the previous work refers to the rapidly advancing tunnel heading in undrained clay. In certain classes of ground, diffusion rates cause problems with stand-up. The next test series turned to the use of a fine rock flour-a very difficult material for tunnels. In Fig. 42 a twodimensional block is being compressed. After compression this specimen is kept firm while exposed by a slight suction while the grid of silvered nylon reflecting beads is placed on the model surface. Ten per cent of this silty soil has particle size finer than $6 \mu \mathrm{m}$; if shaken in the palm of the hand it liquefies and flows away through the fingers. To limit disturbance the tunnel had to be cut on the centrifuge - in Fig. 43 the face is being plugged. There is still slight suction in the soil but when the test begins the water in the black reservoir will come into equilibrium with the aquifer below the model. In flight, the model will swing up into the horizontal plane, and the tunnel air pressure will be raised to prevent failure. 


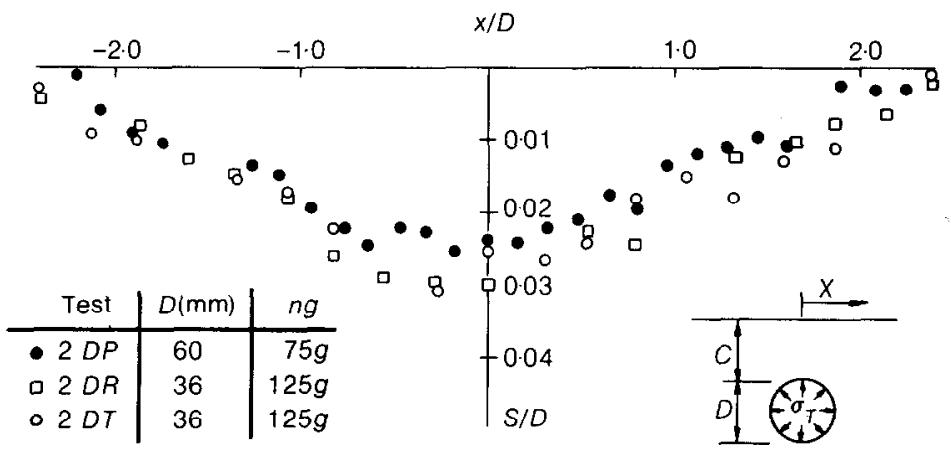

Fig. 41. Plane tunnel settlement trough

As long as the air pressure exceed the groundwater pressure there is no seepage. When the air pressure falls this permeable but incompressible soil allows steady seepage into the tunnel invert. There will be pore pressure transducers in the ground around the tunnel, and in Fig. 20 a steady seepage flow net predicts their steady readings. The magnetic tape record of transducer outputs Fig. 44 then shows the ground behaviour. At the top we see the tunnel air pressure reduced to a just safe level, and then held steady. The displacement transducers show $3 \mathrm{~mm}$ of surface settlement and $7 \mathrm{~mm}$ of crown movement-this is a model at $75 \mathrm{~g}$ so that corresponds to a massive half metre sag of the top of a prototype tunnel. The phenomenon is controlled by rising water levels in the tunnel. As the level of the pool rises above the invert so the seepage into the pool occurs from more and more steeply sloping parts of the tunnel face. The moment when that seepage causes soil to slough off the sloping tunnel wall will be the moment when initial collapse beings. If one looks at the pore pressure outputs, it can be seen that after an initial rise they all settle at the dashed line levels-which correspond to steady seepage, while the pool level rises in the tunnel. Just before final collapse there are transient suctions in the transducers $T$ and $U$ to either side of the tunnel crown. Two photographs taken in flight indicate what is happening just before and just after this event.

In Fig. 45, a photograph just before the event, there has been some settlement of the reflecting beads above the tunnel. The flash light shadow is caused by the tunnel plug. At this stage all the beads are visible to either side of the crown, but a few have disappeared by the tunnel springing. The region above the tunnel, which changes in the next figure, is important.

In Fig. 46 more reflecting beads have disappeared into the shearing soil in precisely the rupture zone where the transient pore pressures were observed. These beads would be $3 / 4 \mathrm{~m}$ apart at prototype scale: this $4 \mathrm{~m}$ tunnel with $12 \mathrm{~m}$ cover under a river would be too dangerous a place to take accurate observations. It is hardly conceivable that a succession of similar prototype tunnels could be brought into this state in order to study such collapse, whereas in the centrifuge we could repeat these ground conditions or change to modelling stand-up of tunnels in overconsolidated clay, as long as the behaviour of remoulded soil is understood.

\section{FLOWSLIDES AND FRACTURES (GOODINGS, D. J. (1979), PADFIELD, C. J. (1980))}

With the tunnel models once we got our data we quickly saw the meaning of our data; we knew what to do to get an accurate result as long as we were testing soil in states near to critical equivalent liquidity and which satisfied plastic theory. In the next two sets of tests I originally hoped to get soil in loose states and generate flowslides. The results did not conform 


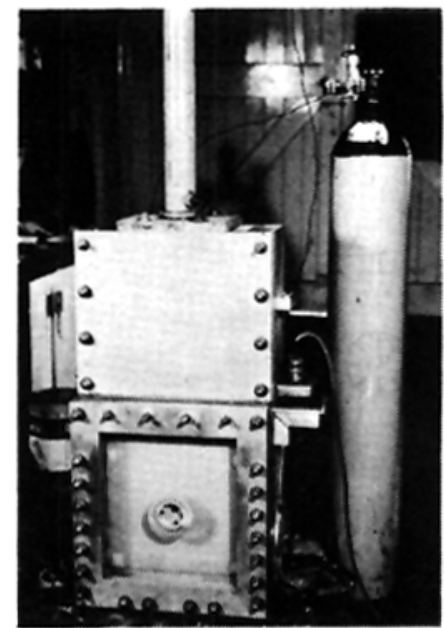

Fig. 42. Plane tunnel model consolidation

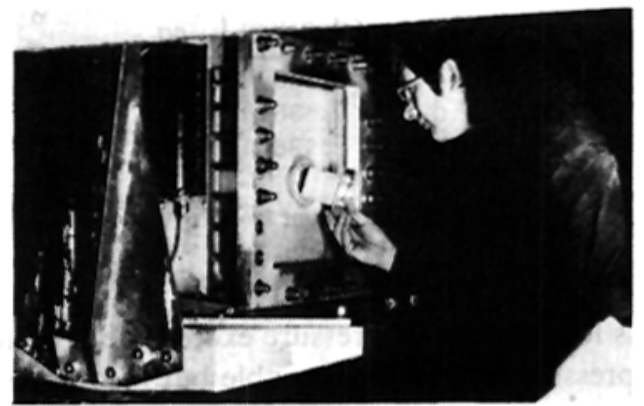

Fig. 43. Insertion of plug

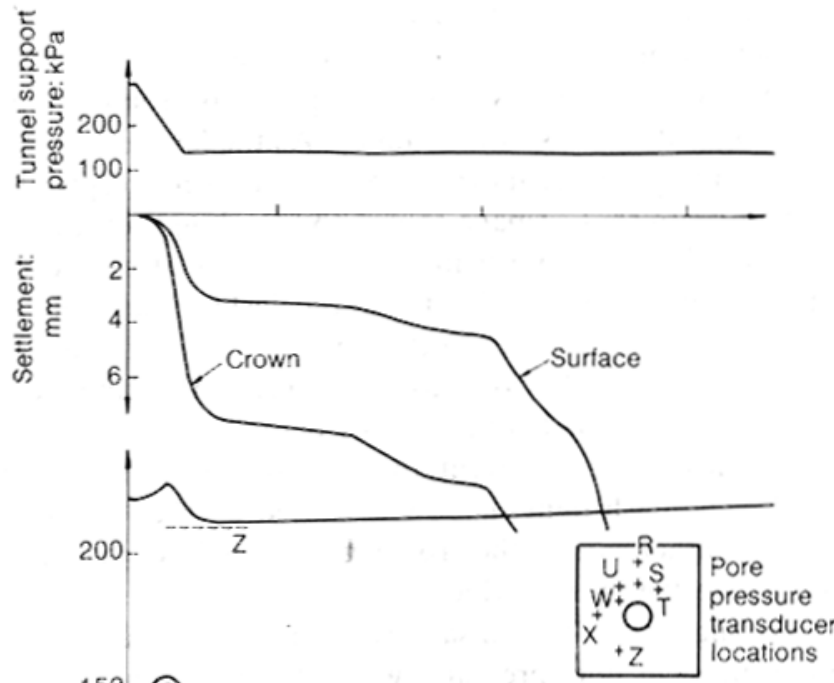

Fig. 44. Transducer outputs 

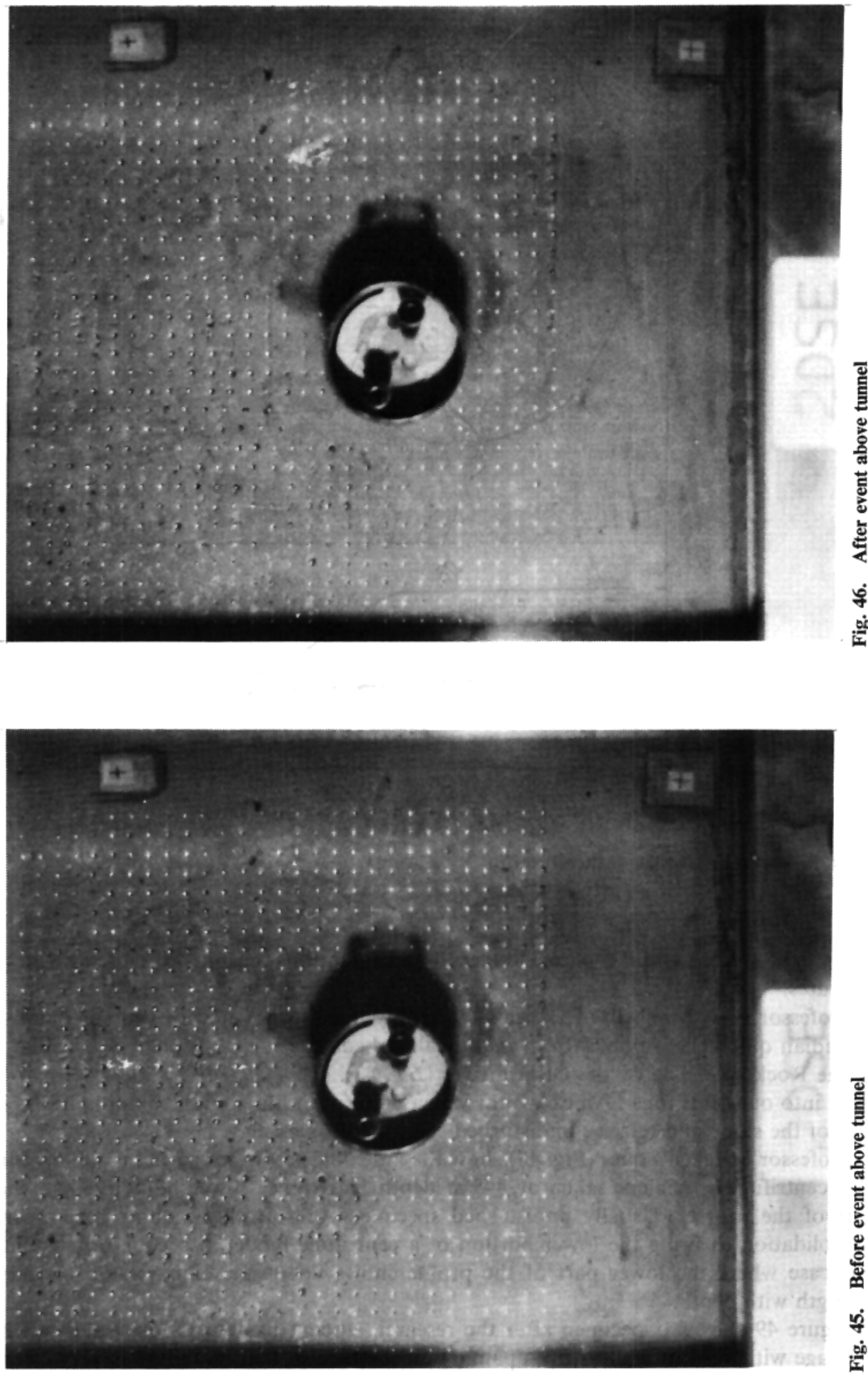


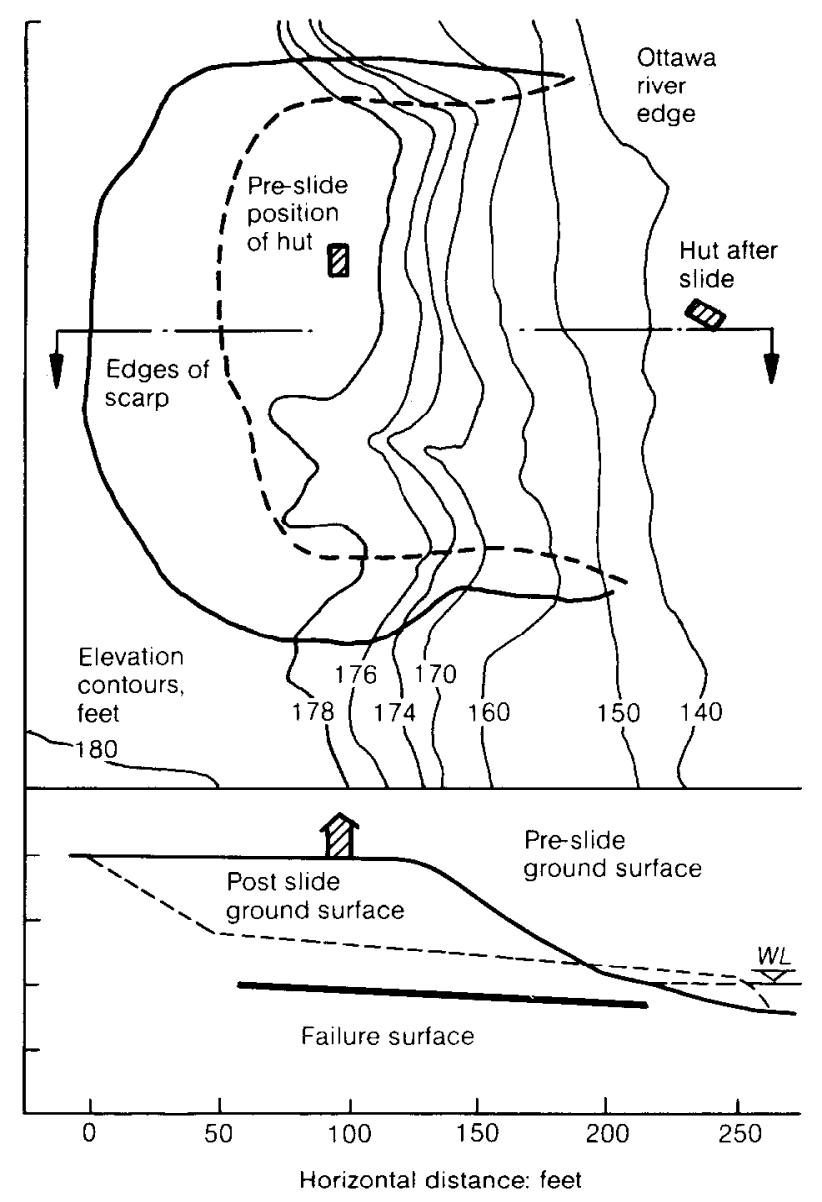

Fig. 47. Rockcliffe landslide (Mitchell, 1970)

to my expectations and it took me longer to understand the meaning of these tests in terms of fractures.

Professor R. J. Mitchell, of Queen's University, Kingston, Ontario, sent some undisturbed Canadian quick clay samples from the so-called Leda clay or Champlain Sea clay at the site of the Rockcliffe slide by the Ottawa river (Fig. 47). This Canadian slide was small enough to fit into our centrifuge. An excavator was used to push horizontal $0.5 \mathrm{~m}$ dia. tubes into the face of the slope and retrieve undisturbed samples of quick clay.

Professor Mitchell's data (Fig. 48) show the index properties found in his site investigation. The centrifuge specimens taken at $4-5 \mathrm{~m}$ depth had rather lower liquidity than the lower part of the profile. Usually undisturbed specimens of soft clay require longer periods of consolidation to bring the lower portion of a centrifuge model into equilibrium, but not in this case where the lower part of the profile shows no plastic compression or increase of strength with depth.

Figure 49 shows a specimen after the research student has cut the clay and put it in the package with vertical white stripes painted on the face so that its failure is very clear on the 


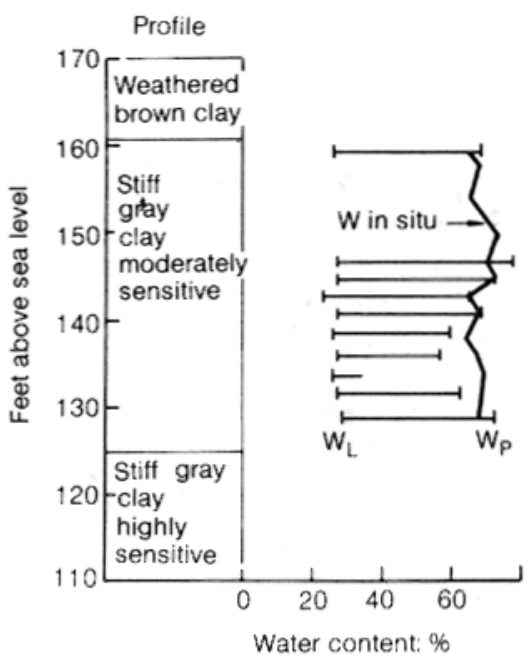

Fig. 48. Rockcliffe landslide soil profile (Mitchell, 1970)

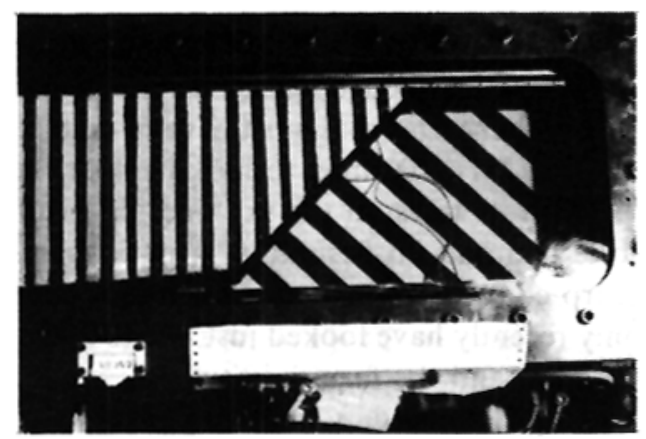

Fig. 49. Before slope failure

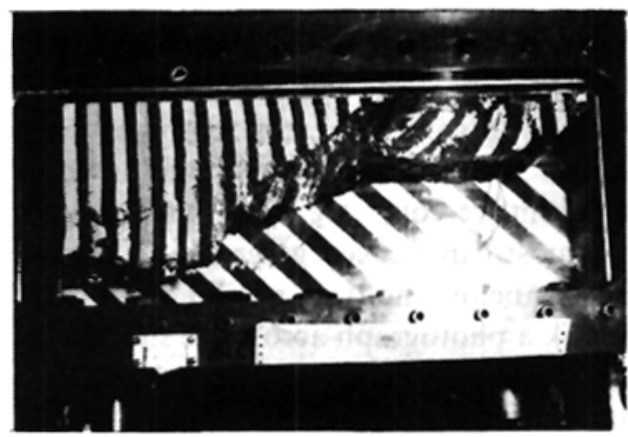

Fig. 50. After slope failure

television screen. The diagonal stripes are at the back of the box. There is provision to apply artesian uplift water pressure below the slope. The soil at depth will be at very high equivalent liquidity. Will we see a flowslide? Figure 50 shows the model after failure.

The Champlain Sea clay is lightly bonded or cemented and has a considerable strength. That is why it resists plastic compression and contains so much water. When it fails with an inclined discontinuity surface the material above the non-circular slip surface fractures and fissures. The fractured mass becomes more permeable and allows more rapid transmission of artesian water pressure. When the pressure was raised the fractured mass immediately responded but the intact mass did not. Most of the high water content of the undisturbed clay is held within an open soil structure and does not play a part in the initial failure of the slope. It is only when the fractured and fissured mass is remoulded during movement downslope that the water all becomes available to transform the remoulded mass of clay into a slurry with high water pressures. A number of tests were made; it was clear that Canadian quick clay problems did not fit my preconceptions of behaviour of very loose soil in an unstable state, which I had expected to be a spontaneous liquefaction rather than this affair of 


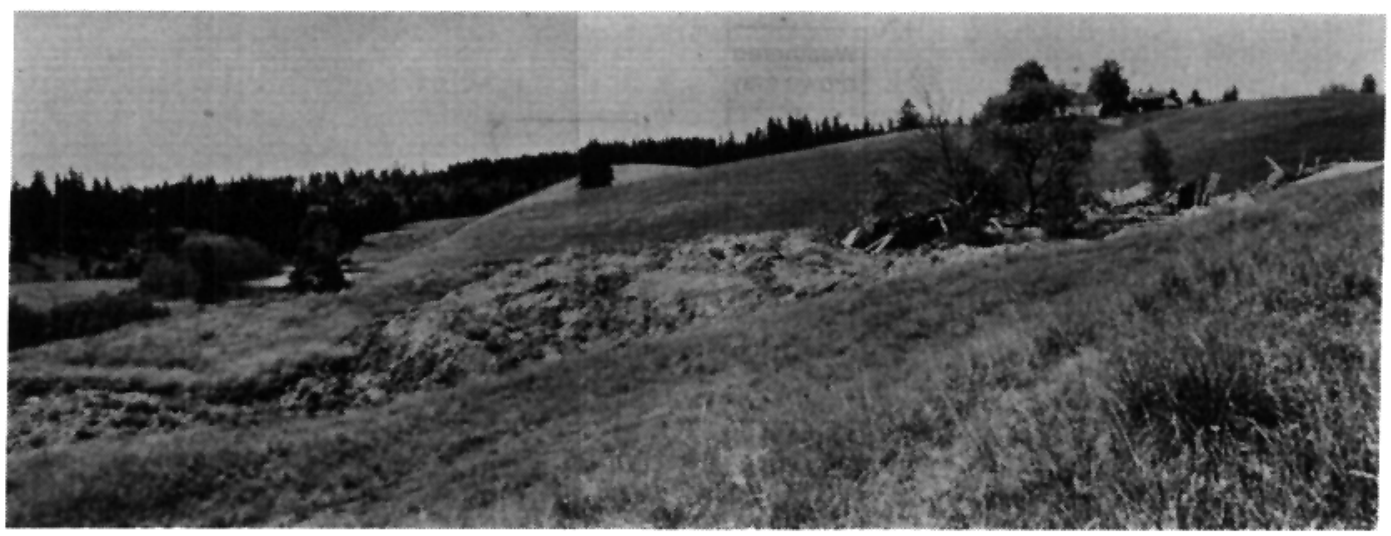

Fig. 51. View of Norwegian quick clay slide

a non-circular discontinuity with fractured material above it. Was this failure something particular to Canadian quick clay?

I have only once visited a quick clay flowslide site and that was in Norway in 1966 when Bjerrum took me to see a flowslide not far from Oslo. He drove down a farm road which ended abruptly at the edge of the slide; standing on the back scarp edge we could see a ruined farm below us, and a stream, beyond which we could see other farms that must have resembled this one. Bjerrum, walked with me down to the ruin (Fig. 51). Turning to look back at the escarpment we could see where the farm road ended with its trees on the sky line. Bjerrum was a most experienced geotechnical engineer, and he had had no hesitation in parking his Mercedes below the trees not far from that back scarp edge. I walked out of the slide area and took a photograph across the site which must only recently have looked just like the farm behind. That farmer was not moving out. What Bjerrum and the farmer knew, and what I had not appreciated, was that quick clay is strong when undisturbed. Compare the slopes of the undisturbed clay and of the remoulded slide material. It is only when remoulded like this debris clogging up the stream that a pore pressure tip thrust into the mass will show pore pressure heads standing several metres above the ground surface.

I do not know how much that Norwegian disaster cost, but it must have been a lot more than the cost of our model tests. The sequence of our test loads is worth explaining. The research student had placed a layer of lead shot on the top surface of the clay, to represent sand layers which occur in some locations. As speed was increased, the first failure occurred at $40 \mathrm{~g}$ - I wish I could show you the TV tape, but much can be seen in Fig. 50. The first failure was on the inclined discontinuity. Nothing further happened until the artesian uplift pressure was increased and the fractured slide mass then moved into this position. The centrifuge speed was then increased to $120 \mathrm{~g}$ and held there for some time-but there was no further failure. At $120 \mathrm{~g}$ this $10 \mathrm{in}$. of soil depth represented $100 \mathrm{ft}$ of prototype. Clearly the intact material has a stiff brittle nature. It is not like a card-house which spontaneously collapses; first the quick clay breaks, leaving a steep back scarp, then the slide debris fractures, becoming permeable, and responds quickly to overlying or underlying water pressure; only when it is remoulded, and in the yield band of cam-clay behaviour, can I represent it by any point on my map. The intact material is not well represented by point $\mathrm{I}$ (hence my question mark) in Fig. 29. 


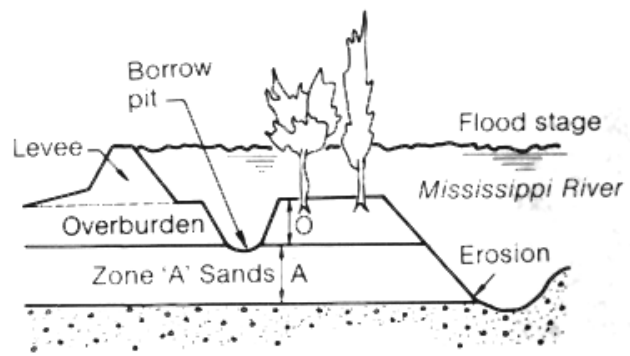

Fig. 52. Section of river bank

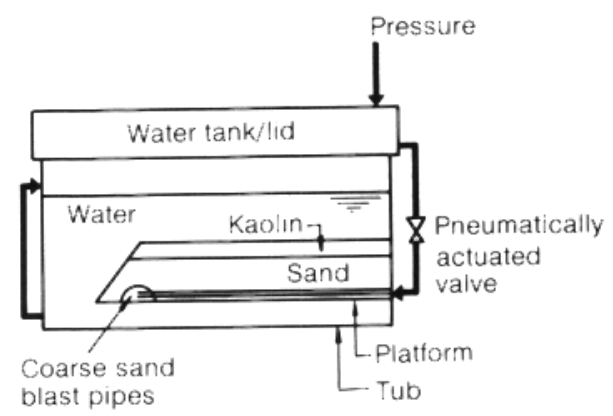

Fig. 54. Model of river bank

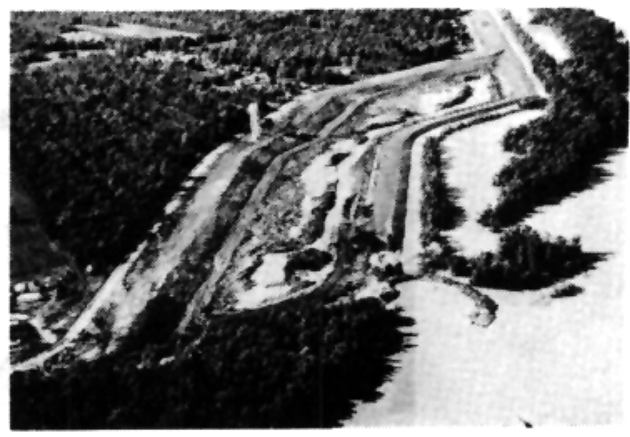

Fig. 53. Montz: set-back levee

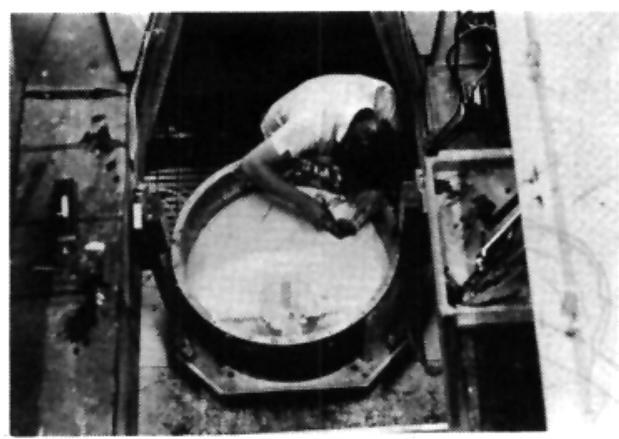

Fig. 55. After a model test

Thinking perhaps more typical flowslide problems occur in sand deposits, the next flowslide locations I considered were the Mississippi River levees, at risk where the meandering river deposited soft sand in point bars and then covered the soft sand bars with layers of silt.

Figure 52 shows a cross-section through a typical flowslide location. When the soft sand in what is called Zone A is eroded and undercut it flows out into the river and is washed away by the flood. Being so undermined, the silty overburden collapses, and as you stand on the levee and look across the river at flood stage you can see the trees disappear into the river. The danger is that the flowslide may undermine a length of the Federal levee. The Corps of Engineers have made a great many measurements of the thickness of point bar sand A and the relative density of the sand.

One significant example was at Montz, near Baton Rouge. In 1973 during the highest flood of record, when the Mississippi river had eroded the bank and trees had fallen into the river, the Corps of Engineers here built a set-back levee (Fig. 53). Fortunately, they had evaluated this location as a region of high risk because of the relative thinness of the overburden, and they had their plant on hand in a guarding programme. It is clearly very important to the engineers in Vicksburg to understand their flowslide risk and it appeared useful to the Waterways Experiments Station for us to study such dangerous events in the centrifuge. According to the Corps of Engineers' empirical criterion, high risk is associated with locations where overburden thickness $\mathrm{O}$ is less than the thickness of point bar sand $\mathrm{A}$. Their question was why thin overburden layers cause more risk, when the critical state theory suggests that thick overburden should increase effective pressure and make loose sand most unstable. 


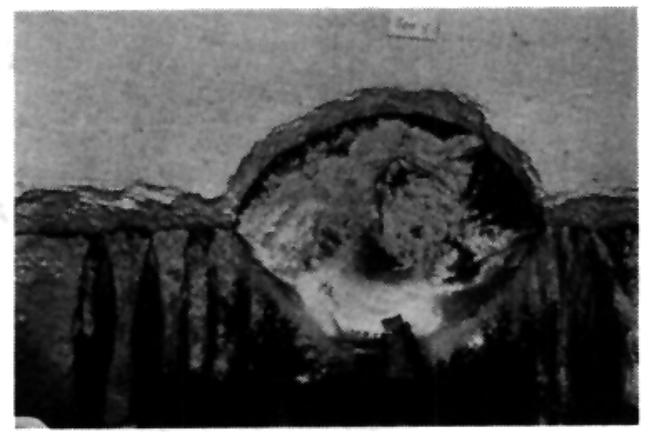

Fig. 56. Model showing breakaway

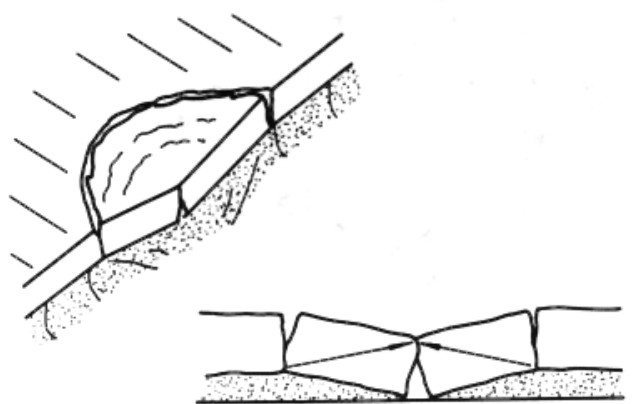

Fig. 57. $0>A$ : arching possible

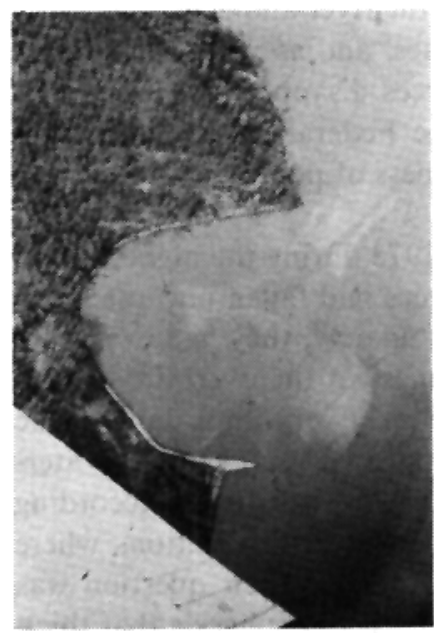

Fig. 59. Aerial view of flowslide feature

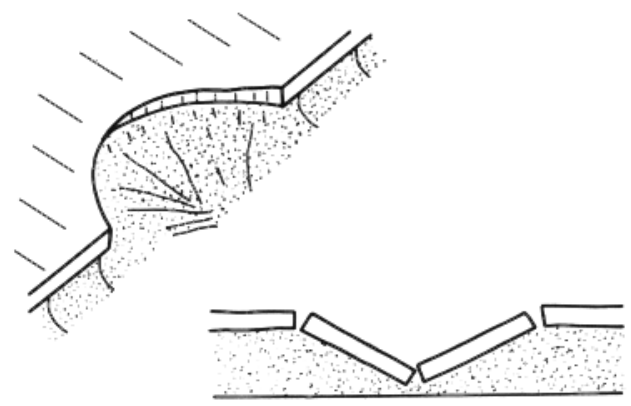

Fig. 58. $0<\mathbf{A}$ : arching impossible

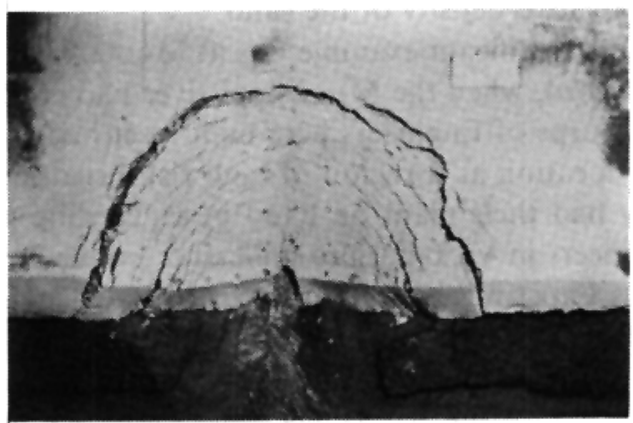

Fig. 60. Model showing cracked slab 
We made a model container (Fig. 54) $850 \mathrm{~mm}$ dia., with a platform on which we could place a layer $A$ of loose sand, and a layer $O$ of overburden clay. We had a water tank above the model connected to blast pipes in the sand. We cut a model river slope. With the model in flight we could open the pneumatically actuated valve, blast sand at the face and see if we could provoke an underwater flowslide crevasse. The whole event is subaqueous. The tank discharges water and the water level in the $850 \mathrm{~mm}$ container rises. We placed the sand as loosely as possible and only lightly consolidated the clay layer. In some tests the clay overburden folded down and did not erode away (Fig. 55).

In other tests the erosion of the sand by the blast pipes caused the slab to crack and break away. Looking at the behaviour of the soft clay overburden in that test (Fig. 56) it was clear that there was a very simple cracked slab explanation of the Corps of Engineers' empirical criterion for flowslide risk.

If the overburden is thicker than the flowsliding sand, then it will settle but may not be carried into the river on the flowing sand because it can arch across the gap. This wedging of blocks of cracked overburden forms a defence against further erosion of the sand (Fig. 57). Alternatively, if the overburden is a thinner crust than the flowsliding sand, then arching is impossible, movement of crust can then occur and erosion can retrogress dangerously (Fig. $58)$.

When I next visited Vicksburg, I was flown along the river and photographed a number of these flowslide crevasse features. Figure 59 looks back along the river behind the aircraft wing. The cracked slab theory not only cxplaincd the basis of the Corps of Engineers' criterion, but also seemed to have correctly shown the features of the prototype.

Unfortunately, the data for our centrifuge model tests at high acceleration were ambiguous. In contrast, in one test (Fig. 60) the blast pipes jammed and did not fire until the end of the test, at one gravity. This result at one gravity was quite unambiguous, and subsequent work was done by the research student outside the centrifuge. This left me with a problem of understanding why the high $g$ model tests did not accurately fit the cracked slab model; I did not resolve that problem until I was preparing this lecture, when I realized that for cracked slab behaviour the overburden soil in the model should have had much lower equivalent liquidity than had been used.

In both the Champlain Sea clay models and the Mississippi river bank models $I$ had tried to get very loose soil in states indicated on Fig. 29 by I. In order to compact the sand we did not consolidate the overburden clay, which was not much below the liquid limit. In tests in the centrifuge the average pressure on the overburden was probably near II; states where Coulomb rupture can occur. In contrast in tests at $1 \mathrm{~g}$, the average stress on the overburden at III was so low that tensile cracking became dominant. We do not have good data on the equivalent liquidity of the prototype overburden, but looking at this map we can see that the equivalent liquidity of the overburden in the ambiguous centrifuge tests at II was too highit had similar equivalent liquidity to the tunnel models at IV and that was why it ruptured and behaved plastically and did not crack. My attempt to model flowslides by creating ultraloose unstable soil in states represented by point I proved to be a wild goose chase. In both of the centrifuge model test series the real problem proved to be correctly understanding how material in states such as III behaved in fracture.

This brings me back to Fig. 31 to explain how I have revised my conceptions about flowslides. In Critical state soil mechanics, for analysis of stressing cases in the region of Coulomb rupture on the dry side of critical states, we suggest simple use of $\phi=\phi_{c}^{\prime}$-the so-called drained angle of friction with zero cohesion, shown as these lines OC and OE, which amount to use of constant stress ratios say $q / p^{\prime}=0.95$ along $\mathrm{OC}$ and $q / p^{\prime}=0.7$ along $\mathrm{OE}$. Soil 
in states of lower equivalent liquidities has peak strengths associated with dilation represented by the lines BAO and EGO, and so is firm and strong. My wrong judgement when I came to consider the flowslide problem was that with firm ground I neglected to consider the risks of sudden change. In a sense the problem was to recognize a new category of behaviour--a fissuring or crumbling of bonded or cemented or firm intact ground that could precede a certain class of flowslide events. It was less important to establish the correctness of the limiting tensile strain or the no-tension criteria of Fig. 27, than to recognize the consequence of sudden changes in permeability when intact ground becomes fissured.

The two test series I have just described suggest to me that these two famous examples of flowsliding (and perhaps other examples as well) are not dominated by behaviour of very soft unstable material at high liquidity, but rather by material that is in states where it is liable to fracture or crumble. Material at high equivalent liquidity may rupture, but it remains impermeable, and as in the tunnel models it behaves plastically. For example, in clay slope failures at equivalent liquidities between 1 and $0 \cdot 6$, negative pore water pressures are generated but a Coulomb rupture does not allow ingress of water along its plane, and suctions can persist for periods of a hundred years. In contrast, at low equivalent liquidities, below 0.5 , at the moment that soil crumbles or becomes fissured it not only dilates as a mass of blocks but also is rapidly suffused with water. It is the suddenness of this change in permeability that transforms the material from a strong intact mass into a flowslide problem.

In such cases there are two features of the high risk flowslide environment. The first feature is an apparent solidity or strength, which tempts people to build levees on an apparently firm overburden layer which they would never trust if the underlying soft sand was exposed. Anyone who was to see such soft sand bar soil in the river bed, moving about first in one location and then in another, would not be inclined to regard it as a safe foundation in the way that the firmly compacted silty overburden soil seems to be solid and strong. Similarly, there is an apparent solidity which tempts people to build housing estates on apparently solid silty clay which is slightly cemented or bonded and has not compressed plastically and which they would never trust if they remoulded the clay and saw how much water it contained. That is the firsi feature of this high risk environment.

The second feature is rapid transformation of this apparently solid ground into a soil avalanche: this occurs much more rapidly than would be calculated from diffusion through pores, because of the change of permeability when tensile cracks open up. The analyses of the theory of plasticity which were discussed in Critical state soil mechanics rely on ductility and impermeability, and should probably only be used for soil with equivalent liquidity over 0.6 , in the rupture or yield bands on this map. Analyses of the theory of plasticity worked well in the case of undrained failure of tunnels in clay at effective pressures not far from critical state, but the occurrence of fissures causes a sudden transformation of the problem. Perhaps the link between the suddenness of hydraulic fracture in dams or wells and the suddenness of a flowslide avalanche is obvious, as are the implications for studies of liquefaction in cyclic loading. My thought in discussing flowslides and fractures in this lecture was to illustrate how study of centrifuge model tests which do not go as expected can change one's thinking about soil mechanics.

\section{CONCLUSION}

Models formed of remoulded soil have explained failure processes, providing accurate and meaningful data. Of course, tests on natural soil proved very useful, bui our achievements with remoulded soil are important to us as a group principally concerned with teaching 
experimental and theoretical soil mechanics. Having established this theoretical and experimental basis, we are now going to turn to the problem of behaviour of dams and embankments in earthquakes.

In this as in all applications, the limitations of centrifuge models remain serious. Even though water content change and change of equivalent liquidities increases the possible scale of prototypes, the corresponding prototypes still remain small. For example, Teton dam Zone 1 material has liquid limit $0 \cdot 26$ and plastic limit $0 \cdot 23$, and with a plasticity index of 3 there is no chance of controlling subtle adjustment of model water content such as an increase of half the plasticity index to produce an equivalent soil that could become a model at one tenth of the prototype effective pressure. So the model must be at prototype density and pressure and there is no chance of forming a whole model of Teton Dam in one of our $850 \mathrm{~mm}$ dia. tubs. Especially as we turn to work with earthquake models we must remember that different processes involve different time scales, and model stress histories seldom replicate all prototype details.

\section{ACKNOWLEDGEMENTS}

All the centrifuge test data that I have quoted and several of the figures have come from the theses of my students. More details of the tests on tunnels can be found in the PhD thesis of Robert Mair and the MPhil thesis of Neil Taylor and in various reports to the Transport and Road Research Laboratory who sponsored that research. Also, details of tests of flowslides can be found in the PhD theses of Deborah Goodings and Christopher Padfield, which formed part of our report to the US Army Corps of Engineers European Research Office who sponsored that research.

In writing this lecture, I have had to make a selection and cannot acknowledge all the contributions of past and present members of the Cambridge Soil Mechanics Group, although I must mention the excellent work of our chief technician Ralph Ward and our senior centrifuge technician Chris Collison.

\section{BIBLIOGRAPHY}

Al-Awadi, A. M. M. (1975). Laboratory and centrifugal model studies of fibrous peat soil. PhD thesis, University of Salford.

Al-Quassab, A. A. M. (1974). The stability of a compacted embankment in centrifugal model tests and in theory. $\mathrm{PhD}$ thesis, University of Manchester.

Al-Saoudi, N. K. S. (1979). Offshore gravity platform model foundations. PhD thesis, University of Manchester.

Al-Zubaidi, J. S. (1975). Behaviour of soil slopes under draw down conditions. MSc thesis, Univcrsity of Manchester.

Atkinson, J. H., Potts, D. M. \& Schofield, A. N. (1977). Centrifugal model tests on shallow tunnels in sand. Tunnels and tunnelling 9, No. 1, 59-64.

Avgherinos, P. J. (1969). Centrifugal testing of models made of soil. PhD thesis, Cambridge University.

Avgherinos, P. J. \& Schofield, A. N. (1969). Drawdown failures of centrifugal models. Proc. 7th Int. Conf. Soil Mech. 2, 497-505.

Barton, Y. O. (1979). Lateral loading of model piles in the centrifuge. MPhil thesis, Cambridge University.

Bassett, R. H. (1973). Centrifugal model tests of embankments on soft alluvial foundations. Proc. 8th Int. Conf. Soil Mech. 2, No. 2, 23-30.

Bassett, R. H. \& Horner, J. (1979). Prototype deformations from centrifugal model tests, Design parameters in geotechnical engineering. Proc. VII Eur. Conf. Soil Mech., Brighton, 2, 1-9.

Beasley, D. H. (1973). Centrifugal modelling of soft clay strata subject to embankment loading. PhD thesis, Cambridge University.

Bolton, M. D., English, R. J., Hird, C. C. \& Schofield, A. N. (1973). Ground displacements in centrifugal models. Proc, 7th Int. Conf. Soil Mech. 1, No. 1, 65-70.

Bolton, M. D., English, R. J., Hird, C. C. \& Schofield, A. N. (1973). Modelling. Proc. Symp. on Plasticity and Soil Mech., Cambridge University, 251-258.

Bolton, M. D., Choudhury, S. P. \& Pang, P. L. R. (1978). Modelling reinforced earth. Ground Engineering 6.

Britto, A. M. (1979). Thin walled buried pipes. PhD thesis, Cambridge University. 
Bucky, P. B. (1931). Use of models for the study of mining problems. American Institution of Mining and Metallurgical Engineers, Tech. Pub. 425, 3-28.

Choudhury, S. P. (1977). A study of reinforced earth retaining walls with sand backfill by centrifugal modelling. $\mathrm{PhD}$ thesis, University of Manchester.

Craig, W. H. (1970). The undrained shear strength of a Boulder Clay in an element and in the mass. MSc thesis, University of Manchester.

Craig, W. H. (1973). Discussion: up-to-date method of investigating the strength and deformability of soils. Proc. 8th Int. Conf. Soil Mech. 4, No. 2, 15-16.

Craig, W. H. (1974). Model studies of the stability of clay slopes. PhD thesis, University of Manchester.

Craig, W. H. \& Boon, M. P. (1977). Model ground anchors under gravitational and centrifugal accelerations. Speciality Session Ground Anchors, 9 th Int. Conf. Soil Mech. Tokyo.

Craig, W. H. \& Yildirim, S. (1979). Modelling excavations and excavation processes. Proc. 6th Eur. Conf. Soil Mech. Vienna.

Cray, P. (1974). Investigation of the problems of thin-walled buried pipes. MSc thesis, University of Manchester.

Davies, M. C. R. (1979). Centrifugal model testing of embankment construction. MPhil thesis, Cambridge University.

Davis, E. H., Gunn, M. J., Mair, R. J. \& Seneviratne; H. N. (1979). The stability of shallow tunnels and underground openings in cohesive material. Cambridge University Engineering Department/D Technical Report 80. To be published in Géotechnique, 30, No. 4 .

Endicott, L. J. (1973). Centrifugal testing of soil models. PhD thesis, Cambridge University.

English, R. J. (1973). Centrifugal model testing of buried flexible structures. PhD thesis, University of Manchester.

Fulsang, L. D. (1971). Preliminary centrifugal studies of the deformation and failure of uniform earth slopes. MSc thesis, University of Manchester.

Fyodorov, I. S. (1936). Investigation of deformation in foundations by means of models. Tech. Phys. U.S.S.R. 3, No. $5,476-488$.

Goldstein, M. N., Misunsky, J. A. \& Lapidus, L. S. (1961). The theory of probability and statistics in relation to the reology of soils. Proc. 5th Int. Conf. Soil Mech. 1, 123-126.

Goodings, D. J. (1979). Centrifugal modelling of slope failures. PhD thesis, Cambridge University.

Hayali, S. N. (1973). A centrifuge model study of the stability of flood embankments. MSc thesis, University of Manchester.

Hird, C. C. (1974). Centrifugal model testing of flood banks. PhD thesis, University of Manchester.

Hird, C. C., Marsland, A. \& Schofield, A. N. (1978). The development of centrifugal models to study the influence of uplift on the stability of a flood bank. Géotechnique 28, No. 1, 85-106.

Hobbs, R. (1975). Finite element analysis of centrifuged soil slopes. PhD thesis, University of Manchester.

Hoek, E. (1965). The design of a centrifuge for the simulation of gravitational force fields in mine models. Jl S. Afr. Inst. Min. Metall. 65, 455-487.

Howsam, P. (1974). Some ground water flow studies using centrifuge modelling techniques. PhD thesis, University of Manchester.

Kutter, B. L. (1979). Behaviour of embankments under dynamic loading. MPhil thesis, Cambridge University.

Larsen, H. (1977). Earth pressures around buried pipes. PhD thesis, Cambridge University.

Larsen, H. \& James, R. G. (1977). Centrifugal model tests of buried rigid pipes. Proc. 9th Int. Conf. Soil Mech. Vol. 1, 567-570.

Le Tirant, P., Loung, M. P., Habib, P. \& Gary, G. (1977). Simulation en centrifugense de Fondations Marines. Proc. 9 th Int. Conf. Soil Mech. Vol, 2, 277-280.

Liu, Hsi-Pint, Hagman, R. L. \& Scott, R. F. (1978). Centrifuge modelling of earthquakes. Geophysics program, Univ. of Washington, Vol. 5, No. 5.

Lyndon, A. (1973). Centrifugal model test of a natural slope failure. PhD thesis, University of Manchester.

Lyndon, A. \& Schofield, A. N. (1970). Centrifugal model test of a short term failure in London clay. Géotechnique 20, No. 4, 440-442.

Lyndon, A. \& Schofield, A. N. (1978). Centrifugal model tests of the Lodalen landslide. Can. Geotech. J. $15,14-31$.

Mair, R. J. (1979). Centrifugal modelling of tunnel construction in soft clay. PhD thesis, Cambridge University.

Malushitsky, Y. N. (1973). Centrifugal simulation of non-consolidated banks and their bases. Proc. 8th Int. Conf. Soil Mech. 4, No. 3, 416.

Malushitsky, Y. N. (1980). The centrifugal model testing of waste heap embankments. English translation of Russian 1975 edition, to be published, Cambridge University Press.

Mikasa, M., Mochizuki, A. \& Sumio, Y. (1977). A study on stability of clay slopes by centrifuge. Proc. 9th Int. Conf. Soil Mech. 2, 121-124.

Mikasa, M. \& Takada, N. (1973). Significance of centrifugal model test in soil mechanics. Proc. 8th Int. Conf. Soil Mech. 1, No. 2, 273-278.

Mikasa, M., Takada, N. \& Yamada, K. (1969). Centrifugal model tests on a rockfill dam. Proc. 7th Int. Conf. Soil Mech. 2, 325-333.

Mitchell, R. J. (1970). On the yielding and mechanical strength of Leda clays. Can. Geotech. 7, 297-312. 
Mitchell, R. J. (1975). Strength parameters for permanent slopes in Champlain Sea Clays. Can. Geotech. J.. 7 Mitchell, R. J. \& Klugman, M. A. (1979). Mass instabilities in sensitive Canadian soils. Engng Geol. 14, 109-134.

Morris, D. V. (1979). The centrifugal modelling of dynamic soil-structure interaction and earthquake behaviour. PhD thesis, Cambridge University.

Ovesen, N. K. (1975). Centrifugal testing applied to bearing capacity problems of footings on sand. Géotechnique 25, No. 2, 394-401.

Padfield, C. J. (1978). The stability of river banks and flood embankments. PhD thesis, Cambridge University.

Pang, P. L. R. (1979). Centrifugal model tests of reinforced earth walls. PhD thesis, University of Manchester.

Pavalakis, G. (1976). An investigation into the performance of a model earth dam. PhD thesis, University of Manchester.

Peck, R. B. (1969). Deep excavations and tunnelling in soft ground. Proc. 7th Int. Conf. Soil Mech., State of Art Volume, 226-290.

Pokrovsky, G. I. \& Boulytcher, V. (1934). Soil pressure investigation on sewers by means of models. Tech. Phys. U.S.S.R. 1, No. 2, 121-123.

Pokrovsky, G. I. \& Fyodorov, I. S. (1935). Investigation by means of models of stress distribution in the ground and the settling of foundations. Tech. Phys. U.S.S.R. 2, No. 4, 299-311.

Pokrovsky, G. I. \& Fyodorov, I. S. (1936). Studies of soil pressures and deformations by means of a centrifuge. Proc. Ist Int. Conf. on Soil Mech. 1, No. 70.

Pokrovsky, G. I. \& Fyodorov, I. S. (1968). Centrifugal modelling in the construction industry. Moscow: Stroiiedat. In draft translation, Building Research Establishment Library, Vol. 1.

Pokrovsky, G. I. \& Fyodorov, I. S. (1969). Centrifugal modelling in the mining industry. Moscow: Niedra. In draft translation Building Research Establishment Library, Vol. 2.

Polshin, D. E., Rudnitsky, N. Y., Chizhikov, P. G. \& Yakovleva, T. G. (1973). Centrifugal model testing of foundation soils in building structures. Proc. 8th Int. Conf. on Soil Mech. 1, No. 3, 203-208.

Pomfret, D. (1976). Centrifugal model tests on cantilever retaining walls with clay back fill. MSc thesis, University of Manchester.

Potts, D. M. (1976). Behaviour of lined and unlined tunnels in sand. PhD thesis, Cambridge University.

Ramberg, H. (1967). Gravity deformation and the earth's crust, as studied by centrifugal models. New York: Academic Press.

Rigden, W. J. \& Rowe, O. W. (1975). Model performance of an unreinforced diaphragm wall. Diaphragm walls and anchorages, 63-67, London: ICE.

Roscoe, K. H. (1969). New laboratory methods of investigating soil behaviour. Proc. 7th Int. Conf. Soil Mech. 3, 517-537.

Roscoe, K. H. (1970). The influence of strains in soil mechanics. Géotechnique 20, No. 2, 129-170.

Rowe, P. W. (1972). The relevance of soil failure to site investigation practice. Géotechnique 22, No. 2, $195-300$.

Rowe, P. W. (1972). Embankments on soft alluvial ground. Q.J. Eng. Geol. 5, 127-141.

Rowe, P. W. (1972). Large scale laboratory model retaining wall apparatus. Stress strain behaviour of soils. Cambridge. Fuulis and Co., Henley, 441-449.

Rowe, P. W. (1975). Applications of centrifugal models to geotechnical structures. Proc. symp. geotechnical structures. University of New South Wales.

Rowe, P. W. (1975). Displacement and failure modes of model offshore gravity platforms founded on clay. Offshore Europe 1975, 218.1-218.6. Aberdeen: Spearhead Publications.

Rowe, P. W. (1975). Inherent difficulties in the application of geotechnical science. Symp. on recent developments in the analysis of soil behaviour and their application to geotechnical structures, 3-29. University of New South Wales.

Rowe, P. W. (1975). Applications of centrifugal models to geotechnical structures. Symp. recent developments in soil mechanics. University of New South Wales, 1-25.

Rowe, P. W. (1975). Displacement and failure modes of model offshore gravity platforms founded on clay. Offshore Europe 1975, 218.1-218.17, Aberdeen: Spearhead Publications.

Rowe, P. W. \& Craig, W. H. (1977). Studies of offshore cassions founded on Oosterschelde sand. Design and construction of offshore structures, pp. 49-55, London: ICE.

Rowe, P. W. \& Craig, W. H. (1978). Predictions of caisson and pier performance by dynamically loaded centrifugal models. Symp. Foundation Aspects of Coastal Structures, Delft, Vol. II, No. 3, 1-16.

Rowe, P. W. \& Craig, W. H. (1979). Applications of models to predictions of offshore gravity platform foundation performance. Proc. Int. Conf. Offshore Site Investigation. London: Society Underwater Technology.

Rowe, P. W., Craig, W. H., Andersen, K. H. \& Selnes, P. B. (1979). Prediction and observation of a model gravity platform on Drammen clay. Proc. Conf. on Behaviour of Offshore Structures, 1979, Paper 34, 427-446, Imperial College, London.

Rowe, P. W., Craig, W. H. \& Proctor, D. C. (1976). Model studies of offshore gravity structures founded on clay. Behaviour of offshore structures conference 1. Norwegian Institute of Technology, Trondheim.

Rowe, P. W., Craig, W. H. \& Proctor, D. C. (1976). Model studies of offshore gravity structures founded on clay. Proc. Conf. on Behaviour of Offshore Structures, 1976, Vol. I, 439-448. Norwegian Institute of Technology. 
Rowe, P. W., Craig, W. H. \& Proctor, D. C. (1977). Dynamically loaded centrifugal model foundations. Proc. 9th Int. Conf. Soil Mech. Vol. 2, 359-364.

Rowe, P. W. \& Smith, I. M. (1980). Comments of the use of physical and analytical models. Int. Symp. Soils under Cyclic and Transient Loading, University of Swansea.

Schmidt, R. M. \& Holsupple, K. A. (1980). Theory and experiments on centrifuge cratering. J. Geophys. Res. 85, No. 2, 235-252.

Schofield, A. N. (1969). Laboratory landslides. Advance, No. 7, October 1969, University of Manchester Institute of Science and Technology.

Schofield, A. N. (1976). General principles of centrifugal model testing and a review of some testing facilities and The role of centrifuge modelling. Articles in Offshore soil mechanics, edited by P. J. George \& D M. Wood. Cambridge University Engineering Department and Lloyd's Register of Shipping.

Schofield, A. N. (1978). Use of centrifugal model testing to assess slope stability. Can. Geotech, J. 15, $14-31$.

Schofield, A. N. \& Wroth, C. P. (1974). Critical states soil mechanics. London: McGraw-Hill.

Scott, R. F. \& Morgan, N. R. (1977). ${ }^{\circ}$ Feasibility and desirability of constructing a very large centrifuge for geotechnical studies. Rep. Nat. Sci. Fdn, 760-170.

Scherbina, V. I. (1973). Investigations of rockfill dam core cracking by centrifugal modelling. Proc. 8th Int. Conf. on Soil Mech. 4, No. 3, 175.

Sketchley, C. J. (1973). The behaviour of kaolin in plane strain. PhD thesis, Cambridge University.

Smith, I. M. and Hobbs, R. (1974). Finite element analysis of centrifuged and built-up slopes. Géotechnique 24, No. 4, 531-559.

Tavenas, F. A. (1978). Centrifugal model tests of the I odalen landslide: Discussion. Can. Geotech. J. 15, $621-624$.

Taylor, R. N. (1979). 'Stand-up' of a model tunnel in silt. MPhil thesis, Cambridge University.

Ter-Stepanian, G. I. \& Goldsteen, M. N. (1969). Multi-storied landslides and strength of soft clay. Proc. 7th Int. Conf. on Soil Mech. 2, 693-700.

Tsytovich, N. A. (1973). Problems of soil and rock mechanics in geomechanics. Proc. 8th Int. Conf. on Soil Mech. 4, No. 2, 149-175.

Vutsel, V. I. (1973). Symposium on centrifugal modelling. Proc. 8th Int. Conf. on Soil Mech. 4, No. 1, $204-210$.

Vutsel, V. I., Dzuka, K. I., Scherbina, V. I., Olimpiev, D. N. \& Fedotova, E. A. Investigation of strain state of slopes. Proc. 9th Int. Conf. on Soil Mech. 2, 165-168.

Waterways Experiment Station (1976). Verification of empirical criterion for river bank stability. US Army Watcrways Experiment Station, Vicksburg, Potomology Report 12-22.

Wilkinson, R. D. (1974). Centrifuge model test of an embankment on Somerset alluvium. MSc thesis, University of Bath.

Wind, H. G. (1976). Interaction of sand and L-shaped walls in centrifuge models. PhD thesis, Cambridge University.

Wright, A. C. S. (1975). Silos: model and field studies. PhD thesis, University of Manchester.

Wroth, C. P. \& Wood, D. M. (1978). The correlation of index properties with some basic engineering properties of soils. Can. Geotech. J. 15, No. 2, 137145.

Wroth, C. P. (1979). Correlations of some engineering properties of soils. Proc. 2nd Int. Conf. Behaviour of Offshore Structures, 2, 121-132, Cranfield: BHRA fluid Engineering.

Yamaguchi, H., Kimura, T. \& Fujii, N. (1977). On the scale effect of footings in dense sand. Proc. 9th Int. Conf. Soil Mech. Vol. I, 795-798.

Yildirim, S. (1976). Centrifuge tests of cuttings in clay. $\mathrm{PhD}$ thesis, University of Manchester.

\section{APPENDIX 1}

\section{CODE OF PRACTICE FOR SAFE OPERATION OF THE CAMBRIDGE GEOTECHNICAL CENTRIFUGE}

\section{Introduction}

The geotechnical centrifuge of Cambridge University Engineering Department (CUED) is a research facility on the West Cambridge Site, formerly called CUED $10 \mathrm{~m}$ centrifuge, and originally conceived by the late Professor K. H. Roscoe in 1969 as a machine capable of testing models at $250 \mathrm{~g}$. It was constructed with funds which came from the University and the Science Research Council, to the design of Mr P. W. Turner, by the Engineering Workshops. It now normally operates with swinging platforms which have surfaces at $4 \cdot 125 \mathrm{~m}$ radius so that the sample is at a working radius of $4 \mathrm{~m}$. At the maximum rotational speed of about $186 \mathrm{rpm}$ the acceleration in the model at $4 \mathrm{~m}$ radius is about $155 \mathrm{~g}$.

Each model must be contained in a strong test package. Of about 20 such packages at present in service about two thirds are circular tubs of $850 \mathrm{~mm}$ internal dia. and $400 \mathrm{~mm}$ depth and the rest are rectangulac boxes

\footnotetext{
${ }^{6}$ This study includes a list of 152 references compiled by Professor Scott up to 1977.
} 
of various dimensions, most with one face including a thick transparent perspex window. Most test packages have undergone a proof test at their own maximum internal pressure, each at the maximum speed obtainable with it, in the presence of an authorized engineer. In subsequent tests in absence of the engineer, the highest acceleration normally authorized is $125 \mathrm{~g}$ at $4 \mathrm{~m}$ radius. A few packages are designed for use at less than maximum speed: such speed-limited packages are proof tested at $1.25 \mathrm{~N}$ gravities before their use at $\mathrm{N}$ gravities is authorized. The swinging platform torsion bars are at present adjusted to accommodate a package not exceeding $900 \mathrm{~kg}$ mass. Thus in its present operations the Cambridge Geotechnical Centrifuge has $125 \mathrm{~g} \times 0.9 \mathrm{t}=$ $112.5 \mathrm{gt}$ capacity at $4 \mathrm{~m}$ radius.

The mechanics of consolidation and of yielding of soil allow the observation, in centrifuge models at reduced scale and increased acceleration, of events similar to full-scale geotechnical events. This centrifuge has two purposes: fundamental research into mechanisms of failure of construction works in soil or of soil-structure interaction; and training of research students, including simulated experience of failure of works of their own construction. Both purposes have been combined in programmes of model tests undertaken by the University under contract to the UK Department of the Environment or similar agencies, leading to publications and to improvements in engineering design. Our charge for use of the centrifuge on contracts with such agencies was set at $£ 500$ per day in 1978 , which should indicate to all users the value of periods of time they use. The efficient and safe use of the centrifuge for a succession of tests by different people using various packages will be ensured by everyone adopting routine procedures set out below. These procedures can be reduced to the following principles. New users require time to become experienced, and the active group of experienced users have a collective responsibility for efficiency and safety, and for training others. Every test must be discussed and programmed in advance, and any new operation must be calculated and proved safe under the direct supervision of a responsible engineer, with open discussion of all work.

\section{Authorized users}

A list of persons currently authorized to use the centrifuge is posted by the Director, and includes names in the following categories.

Engineers: all these are employed by the University or by the Department of Engineering as responsible engineers, and have sufficient experience of the centrifuge to give engineering approval to the tests of other users, to train other users or operators, to operate the centrifuge, or to use the centrifuge as research workers themselves.

Centrifuge operators: all these are engineers or technicians employed by the University or by the Department of Engineering and have sufficient experience of operation of the centrifuge to advise and assist other authorized users, to verify test documents, mount packages, to start the centrifuge, and to undertake activities as directed by a research worker within an agreed programme.

Research workers: all these are research students or engineers or visiting engineers with sufficient experience of the operation of the centrifuge to propose programmes of tests and undertake them when approved, and to help train other users.

The outcome of each experiment is the concern principally of the research workers, who must discuss with one of the engineers all activities that may be required and describe them in a comprehensive programme set out in advance in the standard programme approval document. The research worker will be present during the mounting of the package, and will decide if and when various activities (such as test runs) will actually be undertaken within the programme. When one of the engineers is acting as a research worker then another of the engineers must act as engineer for those tests. The research worker is responsible for producing drawings and calculations which must have satisfied the engineer as to the complete safety of the proposed programme before it is approved. The research worker will complete a balance calculation and obtain the engineer's signature on the standard flight authorization document before each flight or sequence of identical flights of models in the approved programme. The research worker continues to carry on-the-spot engineering responsibility for all decisions and for all activities undertaken in the programme. New research workers must expect to spend many days working with experienced users before they can successfully undertake a 'solo flight'; until then they cannot become authorized users themselves. The facility is constantly changing and the list of persons currently authorized to use the centrifuge also changes, and only includes those with current experience and with a need for authorization; authorization is given by the Director.

The normal running of the centrifuge is the principal concern of the centrifuge operator, who will be responsible for ascertaining that all flights have the engineer's approval, that the packages are assembled and secured in the approved and proven safe manner, and that each operation is recorded in the operations book. The operator who mounts a package and sets up an experiment will also start the test flight to ensure that all operations begin normally but, during extended periods of operation full operational responsibility can be transferred 
to another operator. If at any time the centrifuge operator is not satisfied that the facility and the test activities are normal the operator can either ask the engineer to come to check or terminate the programme without the agreement of the research worker.

\section{Programmes and authorization}

Research workers who wish to use the centrifuge must give full details as required on the standard programme approval document and place this in the planning rack in the Chief Technician's office well in advance. All proposed programmes will be continually reviewed and in general any one week's programme will be finalized during the previous week. The approval of an engineer and of the Chief Technician indicates that the engineer expects to be able to authorize the tests and that assistance can be provided, but from time to time circumstances in one week may necessitate changes in the timing of the programmes for the following weeks and research workers must be prepared for this. For proof tests the calculations must have been checked and approved and authorization documents must have been signed the week before a flight: late calculations inevitably result in programme delay. No forward commitment of centrifuge time is made except by fully approved programme approval sheets placed in the planning rack.

Each flight of a package needs an engineer's signature on a fight authorization sheet. In a flight of a prooftested package a sequence of approved activities can be safely undertaken by a research worker and a centrifuge operator in the absence of the engineer. In proof test flights the engineer will be present. In general with previously proof-tested packages before authorizing a flight the engineer will require confirmation from the research worker that the previous proof tests do cover the proposed activities. If it is proposed frequently to undertake a new activity (such as load application) at some particular acceleration of $n$ gravities, this can be checked by calculation and then proved safe by separate tests in which that activity is performed in the presence of the authorizing engineer at $1.25 n$ gravities before it becomes approved for general use; if $n$ is less than 125 then that activity will be speed-limited to $n$ gravities. The flight authorization sheet will give the value of masses of specimen and counterweight, with calculated swing up speeds which will be checked by the centrifuge operator, as will any other points noted by the engineer.

The working basis for stressing checks of packages on swinging platforms is as follows. The surfaces of the platforms operate at $4.125 \mathrm{~m}$ radius and stressing calculations either relate to acceleration of each mass at its actual radius or to all masses at a nominal $4 \mathrm{~m}$ radius. In calculations all containers should be filled with soil to their maximum working level, and all water vessels or air lines should be filled with water either back to the rotor axis and above or to their vent levels if they are vented into the chamber. Calculations allow for means of loading within the package and assume that soil will become fluidized and apply pressures equivalent to a fluid of density $2100 \mathrm{~kg} / \mathrm{m}^{3}$.

Packages made of ductile mild steel or dural are designed with full plastic stress redistribution at proof test loading with the following properties.

Mild steel has specific gravity 7.83 and may reach $136 \mathrm{MN} / \mathrm{m}^{2}$.

Dural has specific gravity 2.82 and may reach $130 \mathrm{MN} / \mathrm{m}^{2}$.

These working stresses at proof test conditions each include a safety factor of $2 \frac{1}{2}$.

Bolts of Unbrako type are considered ductile if not stressed above $30 \mathrm{MN} / \mathrm{m}^{2}$ in tightening up and are designed for $275 \mathrm{MN} / \mathrm{m}^{2}$ in proof test conditions. This working stress includes a safety factor of 34 . If highly torqued, to cnsure a seal or friction joint, bolts must be discarded after 30 uses.

Where a perspex window is required it is secured by a metal frame with rounded edges not less than $6 \mathrm{~mm}$ radius and is kept free from scoring. In this condition we allow, in calculation for proof tests conditions, that perspex. has specific gravity 1.30 and may reach $7 \mathrm{MN} / \mathrm{m}^{2}$ stress. This working stress includes a safety factor of $2 \frac{1}{2}$ and a stress concentration factor of 2 . In other conditions the stress concentration factor rises to $3 \frac{1}{2}$ or above. Design of a window as a flat plate of thickness $t$, depth $a$, and width $b$, with triangular pressure distribution, increasing from zero at the top to $w$ at the bottom, and with all edges fixed, follows Roark ${ }^{6}$ (case 70 : flat plates) with stress $s$ and deflection $y$ having maximum values

$$
\begin{aligned}
& s=\beta w a^{2} / t^{2} \\
& y=\alpha w a^{4} / E t^{3} \\
& E=2 \cdot 8 \mathrm{GN} / \mathrm{m}^{2}
\end{aligned}
$$

Where other loading or other edge conditions apply the appropriate calculation must be taken from Roark, e.g. for fluid loading see Roark, page 110 for flexure of a beam and neglect the end effects of a flat plate.

${ }^{6}$ Roark, R. J. (1965) Formulas for stress and strain. McGraw-Hill Inc., 4th edn. 
Table A.1.1

\begin{tabular}{lllllllll}
\hline$b / a$ & 0.6 & 0.8 & 1.0 & 1.2 & 1.4 & 1.6 & 1.8 & 2.0 \\
\hline$\beta$ & 0.1308 & 0.1178 & 0.2365 & 0.2777 & 0.3004 & 0.3092 & 0.3100 & 0.3068 \\
$\alpha$ & 0.0016 & 0.0047 & 0.0074 & 0.0097 & 0.0113 & 0.0126 & 0.0133 & 0.0136 \\
\hline
\end{tabular}

The balance calculation must include a manifest of all masses in the flight package, their centroidal heights $x$ above the swinging platform surface, and the offsets $y, z$ of their centroids from the swing centre where $y$ is measured positive downwards in the pit and $z$ is measured positive to the right in plan view. The total mass and centroidal position of each package before flight must be calculated, and if a shift or change of mass is to occur the largest range must be calculated. The counterweight is calculated on the basis that the steel plates weigh $3.557 \mathrm{~kg}$ per mm thickness, and the product of mass times radius of counterweight and package must agree within $\pm 5 \mathrm{~kg} \mathrm{~m}$. The centroid must have $y>-15 \mathrm{~mm}$ to ensure safe swing-up of the platform. The swing-up of each platform is calculated on the basis that swing platforms have mass $127 \mathrm{~kg}$, with centroid $60.9 \mathrm{~mm}$ above platform centre, and that the swing axis is at $x=808.4 \mathrm{~mm}$ and $y=98.4 \mathrm{~mm}$. Swing-up speeds are calculated within $1 / 10 \mathrm{rpm}$.

\section{Operations}

The flight authorization sheet will name the operator: with operators who do not already have a key, then this will authorize them to obtain the centrifuge key from the Chief Technician. The centrifuge operator will be on hand at the time required in the programme with the building key or keys. In preparing for the test the centrifuge operator will check that signatures on documents relate to the test in hand. Before mounting the package in the presence of the research worker the centrifuge operator will check that masses of tests package and counterweight are similar within $5 \mathrm{~kg}$ of those stated in the balance calculation. Before starting the test flight the centrifuge operator will check that the research worker has on hand the set of engineering calculations that relate to the tests, in case these are required by the engineers. The centrifuge operator is responsible for making entries into the operations book which is kept at the centrifuge controls.

Experience has shown that the presence of visitors during centrifuge flight operations is detrimental to safety and efficiency. The only persons who may attend are those properly concerned with a flight operation, such as a collaborator in connection with a research contract or a research worker gaining experience; such persons should be named on the flight authorization sheet and approval for attendance given at the time of authorization. Other persons wishing to visit the centrifuge do so at their own risk, only on days when there are to be no flight operations, and only at the invitation of, and accompanied at all times by, an authorized user.

Before starting the centrifuge the operator will check that all masses in the package and counterweight are properly located and secure, that all people have left the rotor chamber, and that the pit is free from all obstruction or loose objects, and the lids are secure. The pumps and cooling fan are started and the key switch then turned on. The motor starter button is fully depressed, allowing sufficient time for the starter to change to run condition. Availability of all services is ensured and then the Exitation Start button is depressed. The centrifuge operator then goes back to look at the pit and view it from above. On returning to the controls an initial speed increase is pre-set, and swing-up speeds are checked and entered in the operations book. The programme is then started, and activities proceed as directed by the research worker within the agreed programme.

In proof test flights the safety doors must be closed. In other test flights the doors may be left open but no one may generally pass beyond them while the centrifuge speed is increasing, or during any activity in which loads on the package are increasing, without the specific written approval of the engineer on the flight authorization document. During a night flight (particularly when consolidating a clay specimen) the research worker may need to sleep but must remain in the building and be able to be woken up by the centrifuge operator without the operator leaving the control room. To terminate the programme, the Motor Stop button is depressed: the pit is then opened for the research worker by the centrifuge operator.

In the event of accidental removal of any centrifuge drive system (such as loss of cooling system water pressure through human error) the equipment can be reset by depressing the Exitation Start button. In the event of a service failure (such as loss of primary circulation pump) the exitation will automatically be removed from the eddy current coupling. If this is noticed the programme must terminate, but it is preferable to let the 
centrifuge freewheel to rest and also to turn the key switch to the off position (fully anti-clockwise) and remove the keys rather than to depress the Motor Stop button. Occasionally one of the three services can be restarted in flight by re-setting the overload switch on the appropriate starter box.

Table A.1.2 gives the rpm to achieve $n g$, with $g=9 \cdot 81 \mathrm{~m} / \mathrm{s}^{2}$.

Table A.1.2

\begin{tabular}{rrrrrr}
\hline$n$ & rpm & $n$ & rpm & \multicolumn{1}{c}{$n$} & \multicolumn{1}{c}{ rpm } \\
\hline 10 & $47 \cdot 3$ & 50 & $105 \cdot 7$ & 90 & $141 \cdot 9$ \\
15 & $57 \cdot 9$ & 55 & $110 \cdot 9$ & 95 & $145 \cdot 8$ \\
20 & $66 \cdot 9$ & 60 & $115 \cdot 8$ & 100 & $149 \cdot 5$ \\
25 & $74 \cdot 8$ & 65 & $120 \cdot 6$ & 105 & $153 \cdot 2$ \\
30 & $81 \cdot 9$ & 70 & $125 \cdot 1$ & 110 & $156 \cdot 8$ \\
35 & $88 \cdot 5$ & 75 & $129 \cdot 5$ & 115 & $160 \cdot 4$ \\
40 & $94 \cdot 6$ & 80 & $133 \cdot 8$ & 120 & $163 \cdot 8$ \\
45 & $100 \cdot 3$ & 85 & $137 \cdot 9$ & 125 & $167 \cdot 2$ \\
\hline
\end{tabular}

\section{APPENDIX 2}

\section{DESIGN OF THE CAMBRIDGE GEOTECHNICAL CENTRIFUGE}

\section{R. G. James and P. W. Turner}

\section{Introduction}

The Cambridge Centrifuge is intended to provide facilities for testing the material and structural properties of soils, and to enable relatively large specimens and models to be accommodated under conditions of high and nearly uniform acceleration fields. Both fixed and swinging specimen mountings are provided. The centrifuge was designed by P. W. Turner for the Soil Mechanics Group of the University Engineering Department and constructed in the Department's workshops. It is situated at the western side of the West University Site, Madingley Road, and has been funded primarily by the Science Research Council.

\section{General arrangement}

The centrifuge proper (Fig. A.2.1) is housed in a squat cylindrical reinforced concrete shell $3 \mathrm{~m}$ deep and $14 \mathrm{~m}$ in diameter and, since the energy released in a burst could be as much as $10^{7}$ Joules, the rotating parts are positioned well below ground level. The peripheral walls of the cylinder are $1 \mathrm{~m}$ thick and the heavily reinforced sections towards the axis of the centrifuge are designed to sustain a short period rotating force of $225000 \mathrm{~kg}$. In the event of our specimen package becoming completely detached during a test, this will enable the out-of-balance centrifugal forces to be contained until the centrifuge can be brought to rest. Below the cylindrical shell is a tunnel, 1 , in which the drive unit is mounted and which also communicates with a vertical air duct, 2. Vents, 3 and 5 , are positioned so that part of the rotor arm forms the impeller of a centrifugal air pump causing air to flow in through the louvres, 4 , along the tunnel and out through the duct, 2 . About $225 \mathrm{~kW}$ may be dissipated by the rotor arm in the pit and a maximum increase in cooling air temperature of $5{ }^{\circ} \mathrm{C}$ has been permitted. The area of vent, 5 , is variable in order that the air flow may be adjusted. It is undesirable to use an excess cooling air because of the power absorbed. The powerful downward airflow in the pit and the working area above it quickly removes dust, which otherwise can be troublesome, from these spaces. The inner concrete surfaces of the pit are protected with a thick epoxy paint against the abrasive effects of high velocity dust particles.

The vertical shaft, 6 , gives access to the drive unit and its accessories and at the lowest part of the tunnel an automatic sump pump removes drain water which may enter through weep holes in the concrete shell.

Above the cylindrical, shell a layer of soil provides added safety, balances air pressure due to the spinning air body within and, more importantly, prevents bouyancy effects causing the entire concrete vessel to float out of the ground in wet weather. A corridor, $7,2 \mathrm{~m}$ wide runs diametrically across the rotor pit and is separated from it by a floor clad with $10 \mathrm{~mm}$ steel tread plate designed to contain objects which may become detached from the rotor. In this floor, access, observation and instrumentation hatches are positioned and mounting frames for measuring devices, etc. are provided immediately above floor level. Signal, control and power lines 


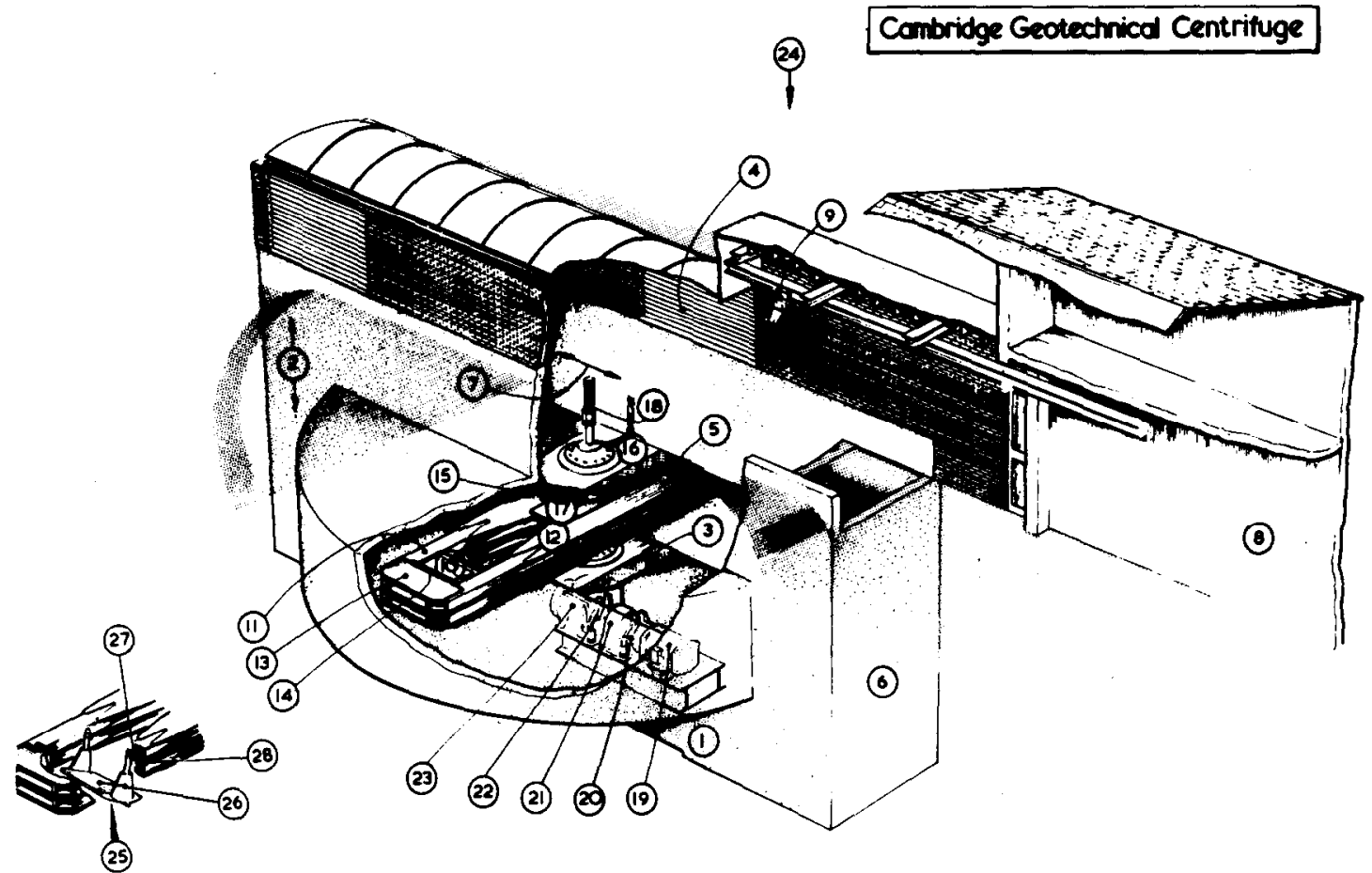

Fig. A.2.1. Cambridge Geotechnical Centrifuge

$\begin{array}{ll}\text { 1. Tunnel } & \text { 8. Observation room } \\ \text { 2. Air duct } & \text { 9. Crane } \\ \text { 3. Air vent } & \text { 10. Specimen box } \\ \text { 4. Louvres } & \text { 11. Spokes } \\ \text { 5. Air vent } & \text { 12. Gussett plates } \\ \text { 6. Shaft } & \text { 13. Bridging structures } \\ \text { 7. Corridor } & \text { 14. Mounting plate }\end{array}$

15. Bearing shaft

16. Horizontal plate

17. Bearing plate

18. Slipring stack

19. Drive motor

20. Electromagnetic brake

21. Eddy current coupling
22. Electromagnetic brake

23. Gearbox

24. Water tower (position of)

25. Swinging carriage

26. Platform

27. Swing arm pivots

28. Torsion bars

from the 80-element slipring stack and the hydraulic lines are routed along this corridor to the control and observation rooms, 8 , and an overhead crane, 9 , enables prepared specimen packages to be transported and mounted into the rotor arm. The corridor is roofed with translucent GRP.

\section{Rotor}

In order that the rotor should be conveniently constructed in the Department's workshops, it was necessary that it be made relatively small, easily handled and assembled in sections. Also cost considerations ruled out the more exotic materials. Further, so that the specimen strong-box design, construction and mounting could. be simplified it was desirable to bring the main arm structure round the back of the specimen box, 10, in a 'sling' configuration. After much consideration of alternative structures it was decided to use the 4-spoke arrangement illustrated, with all the site joints made by means of friction grip bolts. A degree of redundancy in this structure makes it 'fail-safe' and the use of friction grip bolts enables relatively large dimensional tolerances to be accommodated. The rotor then breaks down into the following components.

There are four RHS members, 11 , of $16 \mathrm{in}$. by $8 \mathrm{in}$. in cross-section, about $10 \mathrm{~m}$ long and having gusset plates, 12, welded to them over their central section for attachment to the bearing shaft assembly. Parts of these welds are critically stressed and for this reason the welding was undertaken by the Welding Institute, Abington. A special welding machine was constructed for this purpose, having accurately controlled traverse and feed rates thus ensuring that both mechanical and thermal notching was reduced to an absolute minimum. The welds were heat treated, shot-peened and polished.

Two bridging structures, 13 , link the ends of the spokes and are bolted to them. The line of attachment of the bridge to the spokes is arranged to be off the centroidal line of the latter so that the resulting flexure of the spoke matches the flexure of the bridge and reduces the moment across the joint thus ensuring equal stressing 
of all the bolts. A quarter scale model of this joint was fatigue tested to destruction and the number of cycles to failure agreed well with the predicted value.

The specimen package mounting plate, 14, is an integral part of the bridge structure and is slightly offset downwards so that at maximum $g$ the resultant of centrifugal and gravity forces generates no bending moment at the centre of the rotor arms which are thus in simple tension at the point where the centrifugal forces are greatest.

A fixed specimen mounting plate enables the full capacity of the centrifuge to be utilized, but subjects the specimens to lateral gravitation forces which may be undesirable particularly when the centrifuge is stationary and there is no centrifugal force. For this reason a swinging carriage mounting, 25, is provided. The platform, 26 , on which the specimen is mounted is hung on two swing arms from pivots, 27. These pivots are themselves free to move in a radial direction against the restraint of torsion bars, 28 , thus allowing the swinging platform to seat on the fixed mounting plates when the force on the pivots reaches a predetermined value.

As the centrifuge is accelerated from rest the carriage will swing into the operating position where it is restrained by a stop. Increasing centrifugal force will then cause it to seat on the fixed plates after which point it becomes effectively solid with the rotating structure and there is no further increase in the forces in the swing arms. Satisfactory seating is indicated by electrical contacts. Such an arrangement allows a relatively very light carriage to be employed since the forces in it are reduced by a factor of about 20 compared with a fixed pivot device. The platform was machined out of the solid from aluminium alloy on a numerically-controlled milling machine.

The hollow bearing shaft, 15 , which is turned from a solid blank $0.6 \mathrm{~m}$ in diameter and $2 \mathrm{~m}$ long, carries at either end a self-aligning spherical-roller bearing. All the gravity load is carried by the lower bearing, the upper bearing being mounted on to the concrete structure by a relatively thin horizontal plate, 16, thus allowing axial float by flexure of the settling, differential expansion or inaccurate fitting can be exerted on the bearings. For the same reason a soft, resilient coupling is used to connect the rotor shaft to the drive unit.

A considerable clearance was provided between the rotor arm bearing plates, 17 , and the bearing shaft. After assembly and careful alignment of the axis of the rotor with the axis of the shaft, this clearance was filled with Loctite high strength retaining compound. This technique, combined with friction grip bolting, reduced locked-up stresses to a minimum and considerably facilitates assembly.

Design stress levels and material were determined by, firstly, fatigue requirements and, secondly, ultimate loading requirements. The former must allow at least 10000 start-full load-stop cycles corresponding to at least 10 years' operation. The latter required the structure should have adequate safety factors on static and centrifugal loadings and should not fail under extreme out-of-balance loading, i.e. the loss of one specimen package under full $g$ conditions. High yield steel to BS 4360 Grade $50 \mathrm{C}$ was found to have a small overall advantage over mild steel and consequently was selected for the load-bearing structure. The total weight of the rotor is about $15 \mathrm{t}$.

Above the upper bearing an extension of the shaft carries the slipring stack, 18, comprising 8 hydraulic or pneumatic rings, 4 power rings (i.e. 3 ph. $\mathrm{AC}+$ earth) and 80 low noise signal rings. The rotor is earthed through a slipring since it is considered that under some atmospheric conditions a static charge might otherwise accumulate on it to the detriment of the bearings.

\section{Power requirements}

One of the most intractable problems in the design of a centrifuge is the estimation of the power required to drive it, particularly when it is of novel aerodynamic design and considerably larger than any existing centrifuge for which data are available. Three different approaches were made.

A plot of suitable parameters was made for centrifuges for which it was possible to obtain the necessary information. These plots exhibited a large scatter and application to the Cambridge Centrifuge involved excessive extrapolation. Therefore the results are to be considered as nothing more than a very rough guide.

A purely theoretical approach was made by assuming that the spinning air body in the pit rotated en masse at least over the more significant outer part of its radius. Expressions could then be derived for the torque generated by the relative motion of (a) the rotor arm and the air body, and (b) the air body and the pit. These can then be equated and hence the torque on the rotor calculated. This method appears to provide useful results. It predicts powers in fair agreement with the known values for existing centrifuges of similar configuration (including the model described below) and it indicates the relative importance of design features such as rotor shape, pit shape, roughness of walls, etc.

A rig was constructed in which a wooden model of the rotor arm could be spun inside a suspended hollow cylinder the torque on which could be measured. For practical reasons the model could not be larger than $1 / 12$ scale and hence extrapolation of the results to the full-scale centrifuge involved considerable uncertainties. 
Investigation of the effect of the shape of cross-section of the rotor arm was carried out including the effect of a highly streamlined fairing, of holes and slots and of sharp edges. Also such factors as 'tip clearance' and vertical clearance between rotor and pit, roughness of pit wall (by using various grades of sandpaper) and contour of pit wall were looked at.

These considerations enabled a reasonable compromise to be reached between aerodynamic and structural requirements. For example, the rotor arm, although flat and blade-like, had no fairing; the pit wall, although smooth, is polygonal rather than circular. With regard to absolute power requirements the tests and calculations indicated that $165 \mathrm{~g}$ should be reached with something around $225 \mathrm{~kW}$. It would have been desirable to have doubled this figure in order to take care of uncertainties, but such an expedient would have been too costly. In fact, the $225 \mathrm{~kW}$ drive unit fitted generates rather more than $155 \mathrm{~g}$ at $4.0 \mathrm{~m}$ radius.

\section{Drive unit}

The drive system selected consists essentially of a constant speed electric motor driving the rotor through a water-cooled eddy current coupling and worm and wheel gearbox. The eddy current coupling also serves as a brake. Such a system is moderate in first cost, easily controlled, has low starting current and is economical in running costs for an application where high torque coincides with low slip and vice versa. It also generates a minimum of electrical interference which is an important consideration in a system having numerous and lengthy low-signal circuits.

The arrangement of the drive unit is shown. The $225 \mathrm{~kW}$ A.C. motor, 19, is coupled to the eddy-current coupling, 21, through an electromagnetic brake, 20. A second brake, 22, is situated between the coupling and the gearbox, 23. To start the centrifuge the motor is run up to speed unloaded. The coupling is then energized so as to provide a predetermined constant torque until the selected operating speed of the rotor is reached. This speed is then held to $\pm 0.2 \%$ for the duration of the test run. Provision is also made for a programmable variation in speed. To stop the machine the coupling is de-energized, the motor stopped and locked by means of brake, 20, the coupling re-energized to give a constant-torque slow down, the energy being dissipated by a forced draught water tower, 24 , until a speed is reached at which the coupling becomes ineffective. The brake, 22 , then takes over to bring the rotor to a standstill. The sequence of operations is fully automatic and the machine is provided with comprehensive safety devices to shut it down in the vent of a malfunction and to ensure the safety of the operating personnel.

\section{Performance}

Maximum acceleration at $4 \mathrm{~m}$ radius

Maximum platform pay load at $155 \mathrm{~g}$

$\begin{array}{llr}\text { Maximum acceleration at } 4 \mathrm{~m} \text { radius } & \mathrm{g} & 155 \\ \text { Maximum platform pay load at } 155 \mathrm{~g} & \mathrm{~kg} & 900 \\ \text { Maximum allowable continuous out-of-balance load at } 155 \mathrm{~g} & \mathrm{~kg} & 20 \\ \text { Weight of rotor } & \mathrm{t} & 15 \\ \text { Power of drive motor } & \mathrm{kW} & 225 \\ \text { Run-up time to } 155 \mathrm{~g} & \mathrm{~min} & 10 \\ \text { Run-down time from } 155 \mathrm{~g} & \mathrm{~min} & 7\end{array}$

\section{Note on power requirements}

With the rapidly increasing cost of electricity it was considered advantageous to decrease the air resistance of the rotor by adding a low-drag fairing of symmetrical aerofoil action to the leading and trailing edges of the rotor arms. This fairing was constructed of blown polystyrene reinforced with light alloy and skinned with resin impregnated glass fibre. By this means the power requirement at $155 \mathrm{~g}$ has been reduced by over $20 \%$ and the run-up time reduced to $7 \mathrm{~min}$. 


\section{VOTE OF THANKS}

In proposing a vote of thanks to Professor Schofield, Mr A. M. Muir Wood said:

'Soil mechanics in my time at Cambridge would all have been familiar to Rankine. In the late forties Ken Roscoe was inspired to recognize that, for a new leap forward, soil mechanics needed to be founded more substantially on the fundamentals of plasticity. Professor Roscoe delivered the tenth Rankine Lecture ten years ago and a month later was tragically killed in a road accident.

-Advances in engineering usually spring from a sense of dissatisfaction, much as the oyster responds to grains of sand. Roscoe's lecture in 1970 and Schofield's in 1980 represent true pearls, demonstrating remarkable advances through new experimental techniques combined with the theory, in practical application of what was, at first, purely a set of theoretical concepts.

'I am grateful for this opportunity to pay tribute to the remarkably practical value of the work conducted at Cambridge, most recently under Andrew Schofield's direction, on problems related to tunnelling. I was concerned at the inception of the programme; it has greatly assisted in providing guidance to tunnel design and construction in areas in which trial-anderror was the only prior rational guide - and where error cannot be risked this method tends to lead to conservatism and high cost. The centrifuge is a most powerful tool in providing continuity between theory-cum-experiment at normal laboratory scale, and analysis of behaviour at full, or near full, scale. It also allows, with the ingenuity demonstrated in its manifestations, much insight into the incipient mechanisms of failure. I have been delighted to see this evening such clear illustrations of many of the phenomena that I have encountered at full scale-not $I$ hasten to add of many of the more catastrophic examples.

' There is much future benefit in developing this work and I hope that a task in which I am currently involved, of identifying areas of research need for civil engineering in the next 20 years, will help to encourage funding in this most important area to maintain our competence and lead.

'Thus, it gives me great pleasure in proposing a vote of thanks to Andrew Schofield for a fascinating account of practical and diverse applications of the centrifuge to geotechnical problems and for presenting us with a memorable 20th Rankine Lecture.'

The vote of thanks was accorded with acclamation. 